\title{
Leontief Meets Markov: Sectoral Vulnerabilities Through Circular Connectivity
}

\author{
Ariel L. Wirkierman ${ }^{1}$ (D) Monica Bianchi ${ }^{2}$ Anna Torriero ${ }^{2}$
}

Accepted: 7 July 2021/Published online: 30 August 2021

(C) The Author(s) 2021

\begin{abstract}
Economists have been aware of the mapping between an Input-Output (I-O, hereinafter) table and the adjacency matrix of a weighted digraph for several decades (Solow, Econometrica 20(1):29-46, 1952). An I-O table may be interpreted as a network in which edges measure money flows to purchase inputs that go into production, whilst vertices represent economic industries. However, only recently the language and concepts of complex networks (Newman 2010) have been more intensively applied to the study of interindustry relations (McNerney et al. Physica A Stat Mech Appl, 392(24):6427-6441, 2013). The aim of this paper is to study sectoral vulnerabilities in I-O networks, by connecting the formal structure of a closed I-O model (Leontief, Rev Econ Stat, 19(3):109-132, 1937) to the constituent elements of an ergodic, regular Markov chain (Kemeny and Snell 1976) and its chance process specification as a random walk on a graph. We provide an economic interpretation to a local, sector-specific vulnerability index based on mean first passage times, computed by means of the Moore-Penrose inverse of the asymmetric graph Laplacian (Boley et al. Linear Algebra Appl, 435(2):224-242, 2011). Traversing from the most central to the most peripheral sector of the economy in 60 countries between 2005 and 2015 , we uncover cross-country salient roles for certain industries, pervasive features of structural change and (dis)similarities between national economies, in terms of their sectoral vulnerabilities.
\end{abstract}

Keywords Input-output analysis · Markov chains · Betweenness centrality

\section{Introduction}

Wassily W. Leontief (1905-1999) and Andrey A. Markov (1856-1922) probably never met. Probably, because Leontief's first year as a student at Saint Petersburg

Ariel L. Wirkierman

a.wirkierman@gold.ac.uk

Extended author information available on the last page of the article. 
State University (SPbU) in 1921 coincided with Markov's last year of teaching activities affiliated to that same institution, just before his death. And while their paths may not have crossed, intertwining their contributions reveals foundational insights to study the connectivity in networked structures of socio-economic relations. ${ }^{1}$

Leontief's Input-Output (I-O, hereinafter) method (Leontief 1937) became the cornerstone for analysing the general interdependence and circularity between sectors of an economy (Leontief 1986; Miller and Blair 2009). An I-O table is the matrix representation of the bilateral flows of commodities in terms of monetary units between industries. It may be interpreted as the adjacency matrix of a network whose edges measure input flows whilst vertices represent economic sectors (Olsen 1992). Self-loops (i.e. payments of an industry to itself) are allowed, and in addition to intermediate input flows (i.e. a transaction between two industries) each sector sells its output to final demand (i.e. final consumption, investment and exports) and faces primary cost elements (i.e. wages, taxes, imports), obtaining a gross operating surplus as a residual (UN 2009).

While analyses of the network structure of I-O tables may be found in recent literature (e.g. Xu et al. 2011; McNerney et al. 2013; Tsekeris Tsekeris), the graphtheoretic representation of an I-O system dates back to the work of Solow (1952) and contributions to Morgenstern (1954). More recently, explicit connections between centrality indicators in the emerging field of complex networks (such as Google's PageRank algorithm) and Leontief's I-O model(s) have been drawn (Franceschet 2011).

The extent to which primary incomes and final expenditures are connected distinguishes a closed from an open I-O model. In the former, circularity is complete, to the point that every element of primary costs is mapped into a component of final expenditure, and vice-versa. In the latter model, final expenditure decisions are autonomous, so that primary costs represent a leakage from money flow circularity.

The analytical device of a Markov chain provides a chance process interpretation of the emerging connectivity between nodes in a network (Grinstead and Snell 1997). Superposing such an interpretation to an input-output structure has been thoroughly worked out by Kemeny and Snell (1976, p. 200), mapping an open I-O system into an absorbing Markov chain, i.e. a chain in which intermediate industries are transient states and a primary income component represents the absorbing state. This mapping has been explored in different directions (e.g. Duchin and Levine 2010; Moosavi and Isacchini 2017; Xing et al. 2017; Xing et al. 2018; Kostoska et al. 2020). In particular, Blöchl et al. (2011) devise two centrality measures based on random walks to interpret the propagation of supply shocks through the economy, i.e. shocks that depart from exogenous changes to primary cost components.

Differently from Blöchl et al. (2011), to study betweenness centrality and node vulnerabilities in I-O networks, this paper maps a closed I-O system into an ergodic, regular Markov chain (Kemeny and Snell 1976, p. 37). Such a mapping has been recently used to study the community structure of a global network of inter-industry

\footnotetext{
${ }^{1}$ By connectivity, we mean the number or strength of (independent) paths between any two nodes of a network (Newman 2010, p. 147).
} 
flows with an aggregated, unique final sector (Piccardi et al. 2018). Instead, a key contribution of this paper is to extend the specification of the Markov chain to three different final sectors: (i) the foreign sector, i.e. imports and exports; (ii) the households and government sector and (iii) the profits and investment sector. This has important theoretical implications for the logic of economic circularity, which we explore below.

Departing from the OECD Input-Output Tables (OECD-IOTs) database, we derive a time-series of non-negative, irreducible and row stochastic empirical transition probability matrices, each associated to a regular Markov chain representing the income side of a closed I-O system.

Interpreting the traversal across sectors of the economy as a random walk on an I-O graph, we use the Moore-Penrose inverse of the associated asymmetric graph Laplacian to quantify the betweenness centrality of each sector in the economy (Boley et al. 2011; Ranjan and Zhang 2013). Such a notion of topological centrality captures local, node-level vulnerabilities.

In particular, we consider vulnerability to be defined as "the system's susceptibility to negative [random and/or targeted] shocks" (Cardinale 2019, p. 6), and operationalised — at a local level — by a 'vulnerability gap' (Adger 2006, Table A1, p. 279) between constrained and unconstrained network flows.

Conceptually, betweenness centrality conveys the extent to which a node has the potential for exerting control over the communication between any two other vertices (Freeman 1979). By the same token, a high value of such potential leaves a node in a "state of susceptibility to harm from exposure to stresses" (Adger 2006, p. 268). In fact, in line with previous studies, "for sequential attack the networks are most effectively degraded by removing vertices in decreasing order of betweenness centrality" (Iyer et al. 2013, p. 16, italics added).

We apply this framework to devise a ranking from the most central to the most peripheral sector of the economy for 60 countries between 2005 and 2015, uncovering pervasive features of structural change and (dis)similarities between national economies, in terms of their sectoral vulnerabilities.

After this brief introduction, the rest of the paper is organised as follows. Section 2 recalls preliminary concepts and specifies the mapping of a closed Input-Output system into a regular Markov chain, obtaining a betweenness centrality indicator that quantifies local vulnerabilities. Section 3 describes the path that goes from interindustry data to empirical probability transition matrices, develops an empirical strategy to study cross-country sectoral vulnerabilities, reporting the results obtained. Finally, Section 4 presents a summary of findings and some concluding remarks.

\section{Leontief Meets Markov: Methods}

\subsection{Graphs, Markov Chains and Random Walks}

We quickly recall some standard definitions and results about graph theory and random walks on graphs; for more details the reader is referred to Wilson (1972), Grinstead and Snell (1997), and Kemeny and Snell (1976). 
A graph $G=(V, E)$ is a pair of sets $(V, E)$, where $V$ is the set of $n$ nodes (or vertices) and $E$ is the set of edges (or arcs), consisting of $m$ pairs of nodes of $V$. A directed graph (or digraph) is a graph in which each edge $(\operatorname{arc})$ is an ordered pair $(i, j)$ of vertices. Moreover, a weight $w_{i j}$ may be associated to each edge $(i, j)$, having a weighted (or valued) graph.

A non-negative $n$-square matrix $\boldsymbol{W}=\left[w_{i j}\right]$, representing the adjacency relationships between vertices of $G$, can be associated to the graph (the adjacency matrix); the off-diagonal elements $w_{i j}$ state the strength of the relationship from node $i$ to node $j$, whereas diagonal elements $w_{i i}$ represent the strength of the self-loop of node $i$. The adjacency matrix of a weighted digraph is, in general, asymmetric.

In a directed, weighted graph, the in-degree $d_{i}^{(i n)}$ of node $i$ is the total strength of arcs directed from other nodes to $i$ and the out-degree $d_{i}^{(\text {out })}$ of node $i$ is the total strength of the arcs directed from $i$ to other vertices. If $\boldsymbol{e}^{T}=[1, \ldots, 1]$ is a sum vector, then $\boldsymbol{d}_{(\text {out })}=\boldsymbol{W} \boldsymbol{e}$ and $\boldsymbol{d}_{(\text {in })}^{T}=\boldsymbol{e}^{T} \boldsymbol{W}$. In general, $d_{i}^{(\text {out })} \neq d_{i}^{(\text {in })}$, but $\boldsymbol{e}^{T} \boldsymbol{d}_{(\text {out })}=\boldsymbol{d}_{(\text {in })}^{T} \boldsymbol{e}$.

Throughout the paper we deal with the general case of directed, weighted graphs admitting self-loops and we focus on out-degrees, noting that all the results can be carried out also for in-degrees, by taking the transpose of the adjacency matrix.

Let us also assume that every node has at least one out-going edge which can include self-loops, i.e $d_{i}^{(\text {out })} \neq 0$ for every $i$. In this case, the matrix $\boldsymbol{D}=\widehat{\boldsymbol{d}}_{(\text {out })}$ (containing out-degrees in its main diagonal, and zero elsewhere) is non singular and we can define the matrix $\boldsymbol{P}=\boldsymbol{D}^{-1} \boldsymbol{W}$. Each element of $\boldsymbol{P}, p_{i j}=w_{i j} / d_{i}^{(\text {out })}$ represents the relative strength exerted from $i$ to $j$ (in proportion to the total strength exerted by node $i$ to others).

While matrix $\boldsymbol{P}$ provides us with a structural representation of connectivity for graph $G$, it is possible to superpose a chance process interpretation of emerging connectivity patterns through the device of a finite Markov chain (Grinstead and Snell 1997,p. 405). Each non-negative element $p_{i j}$ may be interpreted as the probability of transitioning from node $i$ (row $i$ in $\boldsymbol{P}$ ) to node $j$ (column $j$ in $\boldsymbol{P}$ ) in the upcoming iteration of the chance process. This process of traversing can be interpreted as a random walk: a sequence of vertices generated from a source node $i$ selecting an edge, traversing the edge to a target vertex $j$ (according to the transition rules codified in $\boldsymbol{P}$ ), and iteratively repeating the transition to another (or the same) node, starting from its immediately previous point of arrival. Thus, matrix $\boldsymbol{P}$ is the transition probability matrix of the Markov chain associated to a random walk on graph $G$, and it is row-stochastic, i.e. $\boldsymbol{P} \boldsymbol{e}=\boldsymbol{e}$.

As we iterate step-wise over this chance process, the probabilities of being on each node as the process unfolds (say, from $t=0$ to $t=1$ ) are given by $\boldsymbol{p}_{(1)}^{T}=\boldsymbol{p}_{(0)}^{T} \boldsymbol{P}$, where $\boldsymbol{p}$ is a probability vector. This iteration process continues $\left(\boldsymbol{p}_{(2)}^{T}=\boldsymbol{p}_{(1)}^{T} \boldsymbol{P}=\right.$ $\boldsymbol{p}_{(0)}^{T} \boldsymbol{P}^{2}$ ) until we (may) reach a fixed point: $\boldsymbol{\pi}^{T}=\boldsymbol{\pi}^{T} \boldsymbol{P}$, where $\boldsymbol{\pi}$ specifies the vector of stationary probabilities.

If the graph $G$ is strongly connected, i.e. for any pair of vertices there is a directed path leading from one vertex to the other, matrix $\boldsymbol{P}$ is irreducible ( $\boldsymbol{P}^{n}$ has only positive entries for some $n$ ). In this case, the associated Markov chain is said to be regular 
(Kemeny and Snell 1976), being possible to be in any state after $n$ steps, no matter what the starting state is. Moreover, by the Perron-Frobenius theorem (Meyer 2000, p. 693), there exists a unique positive vector of stationary probabilities $\pi=\left[\pi_{i}\right]$, describing the long-run proportion of (iteration) periods that a random walker will spend in each node.

But while $\pi_{i}$ provides us with an idea of the relative systemic importance of node $i$, many interesting structural features of connectivity concern relational magnitudes. In particular, (i) what is the average number of steps required to reach node $j$ for the first time, starting from node $i$ and, (ii) what constraint imposes on (i) having to necessarily pass by node $k$ in traversing from $i$ to $j$.

To obtain (i), it is possible to compute the mean first passage time, i.e. the expected number of transitions needed by a random walker starting in source node $i$ to reach target node $j$ for the first time, denoted by $H(i, j)$. By convention $H(i, i)=0, \forall i$ while for $i \neq j, H(i, j)$ is usually obtained using an 'absorbing-chain technique' (for example, see Blöchl et al. 2011). ${ }^{2}$ In particular, if $\boldsymbol{P}_{(-j)}$ is the $(n-1) \times(n-1)$ matrix obtained from deleting the $j$-th row and column of $\boldsymbol{P}$, we have:

$$
H(i, j)=\left[\left(I-\boldsymbol{P}_{(-j)}\right)^{-1} \boldsymbol{e}_{(-j)}\right]_{i}
$$

where $\boldsymbol{e}_{(-j)}$ is an $(n-1)$ sum vector. Note that, computationally, this approach requires to invert $n-1$ matrices, each of dimension $(n-1) \times(n-1)$.

Instead, a key departure of this paper consists in an alternative computation of $H(i, j)$ based on obtaining the Moore-Penrose inverse of (only) one matrix of dimension $n \times n .^{3}$ To see this, besides the transition probability matrix $\boldsymbol{P}$, it is possible to define the (ordinary) asymmetric Laplacian matrix $\boldsymbol{L}=\boldsymbol{\Pi}(\boldsymbol{I}-\boldsymbol{P})$, where $\boldsymbol{\Pi}=\widehat{\boldsymbol{\pi}}$, and which satisfies $\boldsymbol{L} \boldsymbol{e}=\boldsymbol{L}^{T} \boldsymbol{e}=\mathbf{0}$. Then, if we denote by $\boldsymbol{M}=\left[m_{i j}\right]$ the MoorePenrose inverse of $\boldsymbol{L}$, the mean first passage time from source $i$ to target $j$ is given by (Boley et al. 2011, Theorem 15):

$$
H(i, j)=m_{j j}-m_{i j}+\sum_{l=1}^{n}\left(m_{i l}-m_{j l}\right) \pi_{l}
$$

In order to quantify (in number of steps) "how much the restriction of passing through a given vertex $[k]$ represents a detour in going from an arbitrary vertex $i$ to another arbitrary vertex $j$ " (Boley et al. 2011, p. 236), we combine $H(i, k)$ and $H(k, j)$ :

$$
H_{k}(i, j)=H(i, k)+H(k, j)
$$

\footnotetext{
${ }^{2}$ The technique consists in applying the same principles used for absorbing (rather than ergodic) Markov chains to an irreducible chain that does not contain absorbing states (see Grinstead and Snell (1997) and Palacios (1990) and the references therein).

${ }^{3}$ Details on how to compute the Moore-Penrose inverse of a matrix are provided in Meyer (2000, p. 423).
} 
i.e. we need to go from $i$ to $k$ and, then, from $k$ to $j$. By applying Eq. 1, summing over all pairs of source and target nodes and rearranging, we obtain:

$$
\sum_{i=1}^{n} \sum_{j=1}^{n} H_{k}(i, j)-\sum_{i=1}^{n} \sum_{j=1}^{n} H(i, j)=n^{2} m_{k k}
$$

where term (a) in Eq. 2 is the average length of all walks between any pair of nodes restricted to passing by vertex $k$, while term (b) in Eq. 2 is the average length of all walks between any pair of nodes. The difference (a) - (b) represents the "extra distance travelled between two vertices when forced to pass through vertex [ $k]$, summed over all $n^{2}$ pairs of source/destination vertices" (Boley et al. 2011, p. 237).

Note that (a) - (b) in Eq. 2 represents the difference between constrained - of passing by $k$ - and unconstrained network flows across node pairs, respectively. This difference may be interpreted as a 'vulnerability gap' (in the sense of Adger 2006, Table A1, p. 279), where the constrained magnitude captures a node-specific average traversal distance, whilst the unconstrained term captures a 'threshold' average distance between any two nodes. ${ }^{4}$

Given that, throughout this work, we consider graphs with the same number of nodes, (the reciprocal of) $m_{k k}$ in Eq. 2 captures the betweenness centrality of node $k$. In fact, the higher $m_{k k}$ the higher the extra distance imposed by forcing the passage through that node. Thus, a very high value of $m_{k k}$ indicates that $k$ must be a peripheral node of the graph, otherwise the detour would not imply such a large number of steps. In contrast, the lower $m_{k k}$ the lower the required extra distance, so $k$ must be a central node, implying that $i$ frequently passes by $k$ in order to reach $j$.

Hence, the lower $m_{k k}$, the lower the extra distance imposed and the higher betweenness centrality of vertex $k$. Moreover, note that $m_{k k}$ for $k=1, \ldots, n$ can be straightforwardly obtained by extracting the main diagonal of the Moore-Penrose inverse matrix $\boldsymbol{M}$.

More importantly, this notion of betweenness centrality captures local, node-level vulnerabilities for graph $G$. Vertices with (relatively) low values of $m_{k k}$ reveal those nodes which are crucial for the connectedness of the system. If they experience a negative shock, it may be difficult for the system to find alternative, back-up paths to reach other parts of the network. This leads to a key conceptual distinction: the relative systemic importance of node $k$ (measured by its stationary probability $\pi_{k}$ ) may not be particularly high, but if $m_{k k}$ is instead relatively low, a shock to this vertex may severely disrupt the system.

An illustration of this distinction for a directed graph $G$ of $n=7$ nodes is reported below. 5

The network structure in Fig. 1 implies that nodes 1, 2, 3 must necessarily pass by node 4 to reach nodes 5, 6, 7 and vice-versa. Removing node 4 from the graph would imply an unsolvable disruption to the network flow. However, all nodes have

\footnotetext{
${ }^{4}$ With respect to the well-being vulnerability gap in Adger (2006), our formulation has the signs reversed, given that a higher distance would correspond to a lower well-being and vice-versa.

${ }^{5}$ Please note that this is a directed but unweighted graph, to render the example more immediate to grasp.
} 


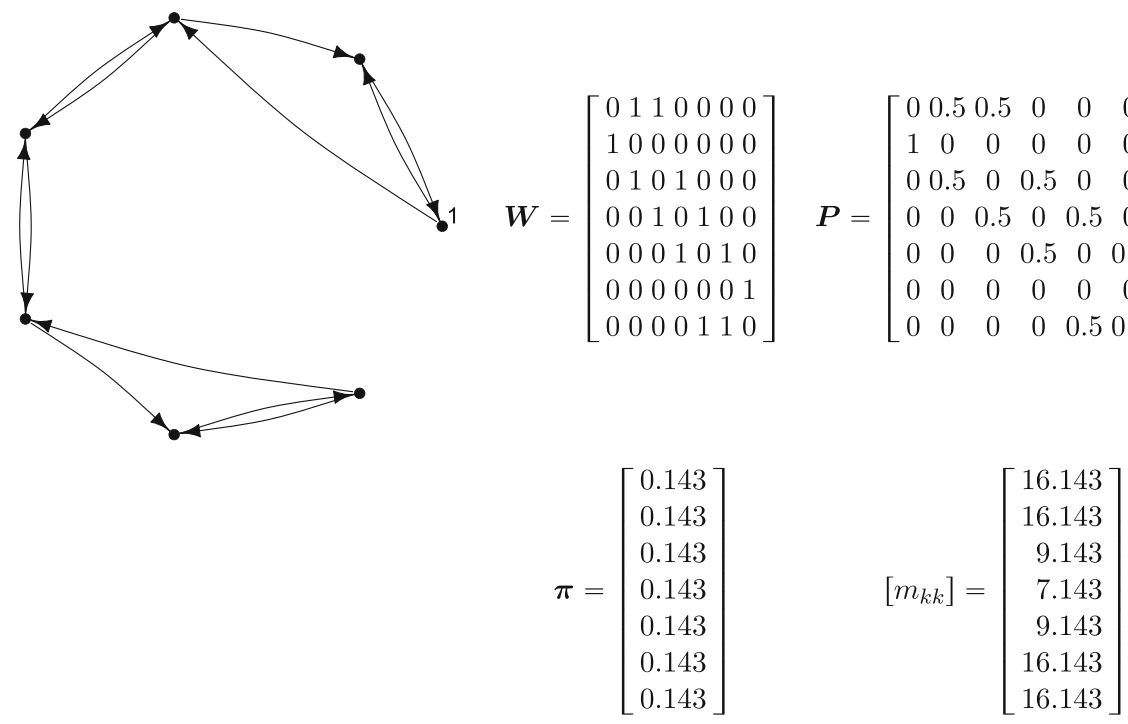

Fig. 1 Graph $G$ and associated adjacency matrix $\boldsymbol{W}$, transition probability matrix $\boldsymbol{P}$, vector of stationary probabilities $\boldsymbol{\pi}$ and vector $\left[m_{k k}\right]$, with the main diagonal of Moore-Penrose inverse $\boldsymbol{M}$ of the asymmetric Laplacian $\boldsymbol{L}=\boldsymbol{\Pi}(\boldsymbol{I}-\boldsymbol{P})$. Nodes in matrices and vectors go from 1 to 7 , nodes in graph are numbered counter-clockwise, starting from node 1 (labelled)

the same stationary probability, $\pi=0.143$, suggesting that they all share the same systemic importance. Instead, the values of vector $\left[m_{k k}\right]$ suggest a clear hierarchy of vulnerabilities. For node $k=4, m_{k k}=7.143$, implying it is the most central node (as expected), whereas vertices 1,2,6 and 7 are the peripheral ones (with $m_{k k}=16.143$ ).

As the example illustrates, whilst conveying different structural properties of network nodes, eigenvector $\left(\pi_{k}\right)$ and betweenness centrality $\left(m_{k k}\right)$ may be shown to be formally related, as well as connected to yet a third notion of node importance, i.e. closeness centrality. Appendix A relates the three centrality concepts by exploring their formulation in terms of mean first passage times using the elements of the Moore-Penrose inverse.

By being formulated within the context of a random walk on graph $G$, the notion of betweenness centrality captured by $m_{k k}$ considers all - rather than only the shortest - network paths, when measuring the influence of a node (Newman 2005). Moreover, as Appendix A shows, $m_{k k}$ incorporates the systemic importance $\left(\pi_{k}\right)$ of all nodes, weighted by the corresponding row $k$ of the Moore-Penrose inverse.

Conceptually, eigenvector centrality reflects the comprehensive effect of a node on other vertices. Closeness centrality indicates how immediately a node is reached, whereas betweenness centrality captures the degree to which a node mediates the comprehensive effects of other vertices (Friedkin 1991). Hence, each indicator captures a different structural property of a node. Our choice of betweenness centrality does not entail an idea of superiority over the other two centrality concepts. We consider that identifying which vertices are more strongly capable of affecting flow transmission between any other two nodes is particularly relevant for analysing local 
vulnerabilities, which occur due to random as well as targeted shocks. In essence, "a point that falls on the communication paths between other points exhibits a potential for control of their communication" (Freeman 1979, p. 221, italics added).

In what follows, this criterion of betweenness centrality highlighting local vulnerabilities will be applied to the analysis of the productive structure of national economies.

\subsection{Closed Input-Output Systems as Regular Markov Chains}

A distinguishing feature of a national economy consists in the comprehensive network of flows of goods and services that are required to produce the final outputs and generate the net incomes ensuring its reproduction. Analytically, this network may be articulated in a dual system of accounting identities, known as the Input-Output (I-O, hereinafter) system (Olsen 1992):

$$
\begin{aligned}
{\left[\begin{array}{cc}
\boldsymbol{X} & \boldsymbol{f} \\
\boldsymbol{y}^{T} & 0
\end{array}\right]\left[\begin{array}{l}
\boldsymbol{e} \\
1
\end{array}\right] } & =\left[\begin{array}{l}
\boldsymbol{x} \\
Y
\end{array}\right] \quad \text { (Expenditure) } \\
{\left[\begin{array}{ll}
\boldsymbol{e}^{T} & 1
\end{array}\right]\left[\begin{array}{ll}
\boldsymbol{X} & \boldsymbol{f} \\
\boldsymbol{y}^{T} & 0
\end{array}\right] } & =\left[\begin{array}{ll}
\boldsymbol{x}^{T} & F
\end{array}\right] \quad \text { (Income) }
\end{aligned}
$$

which, developing the matrix products for a system with $n$ sectors $(n-1$ intermediate industries and one final sector), may be written as:

Matrix form

Scalar form

\begin{tabular}{lll}
\hline $\boldsymbol{x}=\boldsymbol{X} \boldsymbol{e}+\boldsymbol{f}, \quad Y=\boldsymbol{y}^{T} \boldsymbol{e}$ & $x_{i}=\sum_{i=1}^{n-1} x_{i j}+f_{i}, \quad Y=\sum_{j=1}^{n-1} y_{j} \quad$ (Expenditure) \\
$\boldsymbol{x}^{T}=\boldsymbol{e}^{T} \boldsymbol{X}+\boldsymbol{y}^{T}, \quad F=\boldsymbol{e}^{T} \boldsymbol{f}$ & $x_{j}=\sum_{j=1}^{n-1} x_{i j}+y_{j}, \quad F=\sum_{i=1}^{n-1} f_{i} \quad$ (Income)
\end{tabular}

Each element $x_{i j}$ of the square matrix $\boldsymbol{X}$ represents the flow of commodities from industry $i$ to industry $j$ (i.e. inter-industry flows), element $f_{i}$ of column vector $\boldsymbol{f}$ is the flow of commodity $i$ addressed to final uses (final consumption by households and government, investment and foreign demand), while element $y_{j}$ of row vector $\boldsymbol{y}^{T}$ stands for the net incomes, imports of inputs and net taxes paid by industry $j$ in the course of producing its gross output $x_{j}$. Moreover, note that the total final uses $F$ equals total net incomes $Y$, though this is not true at the industry level, i.e. $f_{i} \neq$ $y_{i}$, precisely because inter-industry sales and purchases at the sectoral level will, generally, differ.

The specification above indicates that, when read by row, we describe the demand sources for the products of an industry $i$, i.e. any (other) industries or final uses. Instead, when read by column, we describe the cost structure of an industry $j$.

The duality in expenditure/income accounting relations corresponds to a dual set of flows occurring in the system: every sell of commodities from $i$ to $j$ implies an equivalent purchase from $j$ to $i$, so that to every commodity flow corresponds an equivalent money flow in exchange. Hence, if $\boldsymbol{X}$ represents the matrix of product 
flows, $\boldsymbol{X}^{T}$ will stand for the matrix of money flows paid for the acquisition of inputs by every industry.

A characterising feature of the I-O system (3)-(4) is that it is closed, in the sense that there are no leakages for a monetary unit which is circulating through the economy: every monetary unit spent by final uses is earned by net incomes, and every monetary unit that has been earned by net incomes is spent as final uses. This was the original formulation of the I-O system advanced by Leontief (1949, pp. 214-5): "In a closed system, for example, the level of labor supply would have been directly connected with the level of real income; that is, the quantities of consumers' goods absorbed by the households".

Income and expenditure are mutually determining each other. To see this, we can specify system (3)-(4) in 'intensive' terms, i.e. per unit of gross output of each buying industry:

$$
\begin{aligned}
{\left[\begin{array}{cc}
\boldsymbol{A} & \boldsymbol{a}_{f} \\
\boldsymbol{a}_{y}^{T} & 0
\end{array}\right]\left[\begin{array}{l}
\boldsymbol{x} \\
Y
\end{array}\right] } & =\left[\begin{array}{l}
\boldsymbol{x} \\
Y
\end{array}\right] \quad \text { (Activity levels) } \\
{\left[\begin{array}{ll}
\boldsymbol{e}^{T} & 1
\end{array}\right]\left[\begin{array}{cc}
\boldsymbol{A} & \boldsymbol{a}_{f} \\
\boldsymbol{a}_{y}^{T} & 0
\end{array}\right] } & =\left[\begin{array}{ll}
\boldsymbol{e}^{T} & 1
\end{array}\right] \quad \text { (Price Indices) }
\end{aligned}
$$

where $\boldsymbol{A}=\left[a_{i j}\right]=\boldsymbol{X} \widehat{\boldsymbol{x}}^{-1}$ is a matrix of technical coefficients (element $a_{i j}=x_{i j} / x_{j}$ specifies the monetary units of the product of industry $i$ needed to produce a monetary unit of gross output of industry $j), \boldsymbol{a}_{y}=\left[y_{j} / x_{j}\right]$ is the vector of net incomes induced per unit of gross output, and $\boldsymbol{a}_{f}=\left[f_{i} / Y\right]$ is the distribution of final expenditure categories per unit of net income (a vector of 'propensities' to spend).

When expressed in 'intensive' terms, the accounting identity for expenditure flows (3) becomes the equation system to determine activity levels (5), and the accounting identity for income flows (4) becomes the equation system to determine price indices (6). ${ }^{6}$

Key to this transition is the interpretation of coefficient matrix $\left[\begin{array}{cc}\boldsymbol{A} & \boldsymbol{a}_{f} \\ \boldsymbol{a}_{y}^{T} & 0\end{array}\right]$ as a given, structural description of the economy. Systems (5) and (6) may be read as the right and left eigensystems associated to the eigenvalue $\lambda=1$. Then, by assuming that the coefficient matrix is non-negative (i.e. no negative money flows, including net incomes) and irreducible (i.e. it is possible to reach, even indirectly, any industry from every other industry, including the final expenditure/net income sector), the Perron-Frobenius theorem (Meyer 2000, p. 673) applies: the only positive right and left eigenvectors will be those associated to the maximal (in absolute value) eigenvalue. Given that, as can be seen from Eq. 6, the coefficient matrix is column stochastic (i.e. the sum across rows for each column equals one), the maximal eigen-

\footnotetext{
${ }^{6}$ Each entry $x_{i j}$ in $\boldsymbol{X}$ might be considered to be measured in terms of the amount of physical output of the product of industry $i$ that can be purchased for one monetary unit (Leontief 1986, p. 22). Thus, in the current accounting period, the price of gross output for each industry will be equal to one, as seen in equation system (6).
} 
value will be 1 . Therefore, activity levels $\left[\boldsymbol{x}^{T} Y\right]$ and price indices $\left[\begin{array}{ll}\boldsymbol{e}^{T} & 1\end{array}\right]$ are simultaneously determined as the right and left eigenvectors associated to the unit eigenvalue of the coefficient matrix of structural coefficients.

The essential aspect of connectivity being emphasised here is that of circularity: to determine income we need to know expenditure, and vice-versa. Activity levels and price indices are defined in terms of themselves, as "self-contained (closed) systems require circular definitions" (Brody 1970, p. 84). Circularity implies that there is no beginning nor end to the production process of a national economy (Leontief 1991[1928]).

The circular description of interdependent production provided by the closed Input-Output system (5)-(6) may be interpreted as a regular Markov chain (Brody 1970). Given that (6) implies that the structural coefficient matrix is column stochastic, it is possible to transpose (6):

$$
\left[\begin{array}{cc}
\boldsymbol{A}^{T} & \boldsymbol{a}_{y} \\
\boldsymbol{a}_{f}^{T} & 0
\end{array}\right]\left[\begin{array}{l}
\boldsymbol{e} \\
1
\end{array}\right]=\left[\begin{array}{l}
\boldsymbol{e} \\
1
\end{array}\right]
$$

so that the transposed coefficient matrix in Eq. 7 is a non-negative, irreducible, row stochastic matrix. Therefore, within this context, we can define for an economy with $n-1$ industries and a final sector:

$$
\underset{(n \times n)}{\boldsymbol{P}}=\left[\begin{array}{cc}
\boldsymbol{A}^{T} & \boldsymbol{a}_{y} \\
\boldsymbol{a}_{f}^{T} & 0
\end{array}\right]
$$

as a probability transition matrix derived from the income side of the closed I-O system (3)-(4). Elements of $\boldsymbol{P}$ show the dual side of every transaction in the system:

$$
\begin{array}{ll}
p_{i j}=a_{j i}=x_{j i} / x_{i} & \text { (Payment from } i \text { to } j \text { for inputs per unit of monetary output) } \\
p_{i n}=a_{y i}=y_{i} / x_{i} & \text { (Payment from } i \text { to final sector as a cost component) } \\
p_{n j}=a_{f j}=f_{j} / Y \quad \text { (Payment from final sector to industry } j \text { for its output) }
\end{array}
$$

i.e. commodity flows from $j$ to $i$ (as captured by $a_{j i}$ ) correspond to money flows from $i$ to $j$ (as captured by $p_{i j}$ ). Rather than required inputs per unit of gross output, the transition probabilities $p_{i j}$ "indicate the liabilities incurred per unit of production" (Leontief and Brody 1993, p. 227).

Therefore, each row of $\boldsymbol{P}$ represents the cost structure required by each sector to produce its output. ${ }^{7}$ But what is the chance process interpretation of the probability of transition $p_{i j}$ in this context? It may be framed as follows (Brody 1970, p. 108):

"Sector $[i]$ goes to market and will buy one day from one sector and another day from others. Its purchases may have an apparently irregular pattern. Some days

\footnotetext{
${ }^{7}$ Note that the inputs of net income components are commodities for final uses.
} 
it may not buy anything because inventories are full, to be depleted at random. Nevertheless the probabilities of spending will be allotted to the other sectors as the coefficients $\left[p_{i j}\right]$ - and the real frequency of purchases, followed through, say, a year, will approach this probability".

Thus, the random walker on this Input-Output graph will be one monetary unit (e.g. US\$ 1) that circulates through the system, being iteratively spent into different sectors and earned as income in each production round. The vector of stationary probabilities $\left[\pi^{T} \pi_{n}\right.$ ] would represent the distribution of US\$ 1 across sectors as a fixed point of this iterative circular process. For the case of observed, unit prices of system (6), we have that: $\left[\boldsymbol{\pi}^{T} \pi_{n}\right]=\left[\begin{array}{ll}\boldsymbol{x}^{T} & Y\end{array}\right] /\left(\boldsymbol{x}^{T} \boldsymbol{e}+Y\right)$, i.e. stationary probabilities would coincide with (normalised) observed activity levels. In fact, the potential interest of this analysis resorts in mapping structural changes in the probability transition matrix $\boldsymbol{P}$ (due to, e.g. technological progress or new consumption patterns) into changes in the sectoral distribution of activity levels and relative prices (i.e. price indices) in the economy.

This represents a relevant methodological difference between a regular and an absorbing Markov chain (Kemeny and Snell 1976, p. 37), characterising closed and open I-O models, respectively. In the latter, a shock to the system is introduced by altering the absorbing state of the chain (i.e. net incomes or final demand). Instead, in the former, a shock can be introduced by perturbations to the transition probability matrix $\boldsymbol{P}$ in Eq. 8 (see, e.g. Moosavi and Isacchini 2017). Given that betweenness centrality aims to quantify local vulnerabilities in the event of a random or targeted attack, the first case may be modelled by introducing small random disturbances adding up to zero (to keep matrix $\boldsymbol{P}$ row stochastic), whereas an attack targeted at a specific node $k$ may be implemented as a reduction of transition probabilities $p_{i k}$ of column $k$ by a given factor $\left(\alpha_{k}\right)$, normalising all affected rows (i.e. redistributing $\alpha_{k} \cdot p_{i k}$ to other columns for each affected row $i$ ). If the targeted node $k$ is an industry, this normalisation could be done by allocating $\alpha_{k} \cdot p_{i k}$ to the corresponding entry $p_{i n}$ of the vector of net incomes $\boldsymbol{a}_{y}$ in Eq. 8, which includes imported inputs. Hence, a targeted attack on domestic industry $k$ would imply that other industries would need to source a higher share of input $k$ from abroad. In this targeted case, the procedure would, to a certain extent, resemble an exercise of 'hypothetical extraction' within I-O literature (Miller and Blair 2009, p. 563).

For the empirical exploration below, we will analyse node vulnerabilities by means of the betweenness centrality indicator $m_{k k}$, obtained in Eq. 2. Within a random walk on the I-O graph, each node represents a sector, so the extra distance in traversing from $i$ to $j$ - imposed by forcing the passage through sector $k$ quantifies the intermediary role of an industry (or final sector) in the economy. The lower the value of $m_{k k}$, the more vulnerable the economic system will be to a reduction in the productive capacity of sector $k$. Thus, it is possible to set up a ranking from the most central (lowest $m_{k k}$ ) to the most peripheral (highest $m_{k k}$ ) sectors. 


\section{An Empirical Exploration: Results and Discussion}

\subsection{Dataset Characteristics and Preparation: From Inter-Industry Data to Probability Transition Matrices}

Our data source is the OECD Input-Output Tables (OECD-IOTs) database. ${ }^{8}$ We consider data for years covering the period 2005-2015. The original database has I-O tables for 64 countries, each with a 36 industry-level disaggregation based on the standard classification ISIC Rev. 4.

A key data requirement of the exercise is that the structural matrices considered should be non-negative and irreducible. In order to comply with these requirements, 4 countries had to be discarded. ${ }^{9}$ Moreover, the 36 original industries had to be aggregated into 32 activities. ${ }^{10}$ Appendix $\mathrm{C}$ provides a dictionary with the ISO3 country codes and the sectoral classification used throughout the paper.

Besides the 32 intermediate industries, a closed Input-Output system needs to carefully specify its final sector(s). This is a crucial aspect of the data preparation process, if consistency is to be obtained between theoretical magnitudes and empirical figures. In particular, our probability transition matrices are required to be non-negative. However, taking into account an Input-Output table (IOT, hereinafter) in full detail (i.e. including taxes net of subsidies, separate income components and inventories) involves dealing with cells that, a priori, may contain negative values. We describe below the procedure to map extracted IOTs into a series of empirical transition probability matrices.

For each national economy, we specified an empirical closed system which contains three final sectors: (i) the foreign sector, i.e. imports and exports (labelled 991XM); (ii) the households and government sector (labelled 992YC) and (iii) the profits and investment sector (labelled 993PI). This has important theoretical implications for the logic of economic circularity. Exports become the 'inputs' to finance the acquisition of imports (i.e. exports will represent the 'cost structure' of imports). Earned wages and taxes (net of subsidies) become (private and public) final consumption spent. Finally, profits (i.e. gross operating surplus) obtained by industries become investment (i.e. gross fixed capital formation). The distinction between different income-expenditure connections allows for a richer analysis of general interdependence in a closed model.

In order to make these distinctions, it was crucial to map detailed national accounting items contained in each IOT to the analytical categories just defined. Table 1

\footnotetext{
${ }^{8}$ Accessed at: http://www.oecd.org/sti/ind/input-outputtables.htm.

${ }^{9}$ The countries excluded from the analysis were: BRN (Brunei Darussalam), LVA (Latvia), MLT (Malta) and SGP (Singapore). Exclusions were due to the fact that some industries in these countries had negative gross value added.

${ }^{10}$ Three aggregations were performed: (i) the three original mining industries (mining of energy products, non-energy products and mining support services) were combined into a single mining sector, (ii) Coke and refined petroleum, chemicals and pharmaceutical products were combined into a single sector and (iii) the service activities of private households were added to other personal services.
} 
Table 1 Mapping between OECD-IOT final sector items and model analytical categories (Each analytical category (991XM, 992YC, 993 PI) may include several OECD-IOT items)

\begin{tabular}{|c|c|c|c|c|}
\hline \multicolumn{5}{|c|}{ Rows of a national OECD Input-Output table (Income categories) } \\
\hline Label & ISO & Sector & $O E C D$ code $(s)$ & $O E C D$ sector \\
\hline \multirow[t]{2}{*}{ 991XM } & $\mathrm{XM}$ & Foreign sector (Imports & & \\
\hline & & and Exports) & IMP_01T03 to IMP_97T98 & Imported intermediate inputs of each industry's product \\
\hline \multirow[t]{5}{*}{$992 \mathrm{YC}$} & $\mathrm{YC}$ & Households and & & \\
\hline & & Government sector & TXS_IMP_FNL & Taxes less subsidies on intermediate and final imported products \\
\hline & & & TXS_INT_FNL & Domestic taxes less subsidies on intermediate and final products \\
\hline & & & OTXS & Other taxes less subsisdies on production \\
\hline & & & LABR & Compensation of Employees \\
\hline \multirow[t]{2}{*}{$\overline{993 \mathrm{PI}}$} & PI & Profits and Investment & & \\
\hline & & sector & GOPS & Gross operating surplus and mixed income \\
\hline \multicolumn{5}{|c|}{ Columns of a national OECD Input-Output table (Expenditure categories) } \\
\hline Label & ISO & Sector & $O E C D$ code $(s)$ & $O E C D$ sector \\
\hline \multirow[t]{3}{*}{$991 \mathrm{XM}$} & XM & Foreign sector (Imports & & \\
\hline & & and Exports) & EXPO & Exports \\
\hline & & & CONS_NORES & Consumption by non-residents in the domestic terriotory \\
\hline \multirow[t]{5}{*}{$992 \mathrm{YC}$} & $\mathrm{YC}$ & Households and & & \\
\hline & & Government sector & $\mathrm{HFCE}$ & Household Final Consumption Expenditure \\
\hline & & & NPISH & Expenditure by non-profit institutions serving households \\
\hline & & & GGFC & General Government Final Consumption \\
\hline & & & CONS_ABR & Consumpion by domestic residents abroad \\
\hline \multirow[t]{2}{*}{ 993PI } & PI & Profits and Investment & & \\
\hline & & sector & GFCF & Gross fixed capital formation \\
\hline
\end{tabular}

Source: Authors' elaboration based on OECD-IOTs Database, 2018 edition

below reports the connection for both income (i.e. IOT rows) and expenditure (i.e. IOT columns) sides of the I-O system.

Besides the aggregation of accounting items into the three analytical final sectors, two further adjustments were done to obtain a non-negative matrix. First, for those industries with substantial agricultural subsidies (e.g. selected EU countries), other taxes less subsidies on production (item OTXS in Table 1) were negative to the extent of rendering the entire income of the Households and Government sector (992YC) negative. For those cases, OTXS were added to the gross operating surplus (GOPS) of the industry (so moved to analytical category $993 \mathrm{PI}$ ), as subsidies artificially inflate the operating surplus of the firm. Secondly, for those industries with a negative gross operating surplus (GOPS), this accounting item was netted from the Households and Government sector ( $992 \mathrm{YC}$ ) as, when losses by firms are distributed, it would be households owning them and government collecting corporate taxes that would face the ultimate consequences. In those sectors where such a correction was made, GOPS was allocated a value equal to zero.

The last aspect of the data preparation procedure concerns the treatment of inventories (accounting item INVNT in the OECD-IOT database). These were removed from the analysis, so all levels of income items were recalculated — using the current technical coefficients - for a final demand which excludes inventories.

To illustrate the outcome of this data preparation process, Panel (a) of Table 2 reports an articulated selection of cells of the empirical I-O table for the USA (year 2015), arranged into analytical categories, whereas Panel (b) establishes the correspondence with the matrix, vector and scalar symbols to be used in the theoretical operations that follow. 
Table 2 Mapping between an empirical IOT and analytical matrix categories

\begin{tabular}{|c|c|c|c|c|c|c|c|}
\hline \multirow[t]{2}{*}{ Panel (a) } & \multicolumn{7}{|c|}{$\begin{array}{l}\text { Visualisation of selected cells of the empirical IOT for the USA, year } 2015 \\
\text { (cell values in current US\$ mln.) }\end{array}$} \\
\hline & 01T03AGR & 05T09MIN & . $86 \mathrm{~T} 88 \mathrm{HTH}$ & 90T98OTS & $991 X M$ & $992 \mathrm{YC}$ & 993PI \\
\hline 01T03AGR & 61596.7 & 128.6 & 1568.9 & 1247.8 & 51438.7 & 101803.6 & 584.1 \\
\hline 05T09MIN & 5632.2 & 83952.6 & 2007.4 & 2417.3 & 28340.4 & 10003.5 & 21077.0 \\
\hline : & : & : & : & : & $:$ & : & : \\
\hline $86 \mathrm{~T} 88 \mathrm{HTH}$ & 1.8 & 8.5 & 53486.1 & 1459.5 & 3081.9 & 2127495.1 & 491.5 \\
\hline 90Т98 & 319.3 & 262.1 & 10449.6 & 12810.3 & 15264.2 & 726229.1 & 11718.0 \\
\hline 991XM & 22551.7 & 9206.4 . & 62315.7 & 21850.2 & 0.0 & 894328.9 & 322689.8 \\
\hline $992 \mathrm{YC}$ & 69156.0 & 117825.8 & 1106981.6 & 357154.1 & 11698.3 & 456510.7 & 30788.8 \\
\hline 993PI & 126122.3 & 200076.3 & 183357.3 & 133711.4 & 0.0 & 0.0 & 0.0 \\
\hline
\end{tabular}

Panel (b) Schematic representation of a theoretical IOT

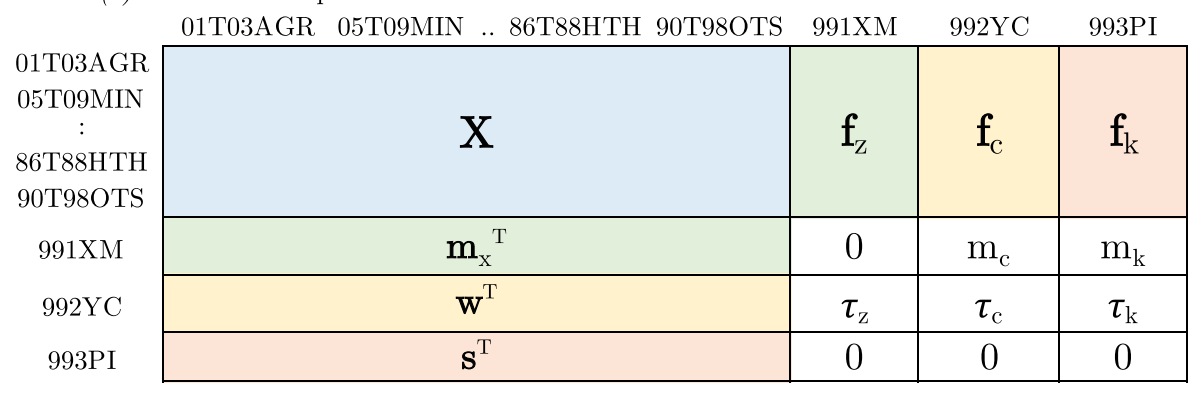

Source: Authors' elaboration based on OECD-IOTs Database, 2018 edition

To derive a non-negative, irreducible and row stochastic empirical transition probability matrix, we consider the income side of the I-O system (in an analogous way to system (4) above):

$$
\left[\begin{array}{llll}
\boldsymbol{e}^{T} & 1 & 1 & 1
\end{array}\right]\left[\begin{array}{cccc}
\boldsymbol{X} & \boldsymbol{f}_{z} & \boldsymbol{f}_{c} & \boldsymbol{f}_{k} \\
\boldsymbol{m}_{x}^{T} & 0 & m_{c} & m_{k} \\
\boldsymbol{w}^{T} & \tau_{z} & \tau_{c} & \tau_{k} \\
\boldsymbol{s}^{T} & 0 & 0 & 0
\end{array}\right]=\left[\begin{array}{llll}
\boldsymbol{x}^{T} & Z & C & I
\end{array}\right]
$$

Developing the matrix products we obtain expressions for gross output and final expenditure categories:

$$
\begin{aligned}
\boldsymbol{x}^{T} & =\boldsymbol{e}^{T} \boldsymbol{X}+\boldsymbol{m}_{x}^{T}+\boldsymbol{w}^{T}+\boldsymbol{s}^{T} \\
Z & =\boldsymbol{e}^{T} \boldsymbol{f}_{z}+\tau_{z} \\
C & =\boldsymbol{e}^{T} \boldsymbol{f}_{c}+m_{c}+\tau_{c} \\
I & =\boldsymbol{e}^{T} \boldsymbol{f}_{k}+m_{k}+\tau_{k}
\end{aligned}
$$

(Gross output by industry)

(Exports)

(Consumption)

(Investment) 
This system of accounting identities can be expressed in intensive terms, to derive a system of price indices:

$$
\left[\begin{array}{llll}
\boldsymbol{e}^{T} & 1 & 1 & 1
\end{array}\right]\left[\begin{array}{cccc}
\boldsymbol{X} & \boldsymbol{f}_{z} & \boldsymbol{f}_{c} & \boldsymbol{f}_{k} \\
\boldsymbol{m}_{x}^{T} & 0 & m_{c} & m_{k} \\
\boldsymbol{w}^{T} & \tau_{z} & \tau_{c} & \tau_{k} \\
\boldsymbol{s}^{T} & 0 & 0 & 0
\end{array}\right]\left[\begin{array}{cccc}
\widehat{\boldsymbol{x}}^{-1} & \mathbf{0} & \mathbf{0} & \mathbf{0} \\
\mathbf{0}^{T} & Z^{-1} & 0 & 0 \\
\mathbf{0}^{T} & 0 & C^{-1} & 0 \\
\mathbf{0}^{T} & 0 & 0 & I^{-1}
\end{array}\right]=\left[\begin{array}{llll}
\boldsymbol{x}^{T} & Z & C & I
\end{array}\right]\left[\begin{array}{cccc}
\hat{\boldsymbol{x}}^{-1} & \mathbf{0} & \mathbf{0} & \mathbf{0} \\
\mathbf{0}^{T} & Z^{-1} & 0 & 0 \\
\mathbf{0}^{T} & 0 & C^{-1} & 0 \\
\mathbf{0}^{T} & 0 & 0 & I^{-1}
\end{array}\right]
$$

therefore obtaining (analogously to system (6) above):

$$
\left[\begin{array}{llll}
\boldsymbol{e}^{T} & 1 & 1 & 1
\end{array}\right]\left[\begin{array}{cccc}
\boldsymbol{A} & \boldsymbol{a}_{z} & \boldsymbol{a}_{c} & \boldsymbol{a}_{k} \\
\boldsymbol{a}_{m}^{T} & 0 & a_{m}^{c} & a_{m}^{k} \\
\boldsymbol{a}_{w}^{T} & a_{\tau}^{z} & a_{\tau}^{c} & a_{\tau}^{k} \\
\boldsymbol{a}_{s}^{T} & 0 & 0 & 0
\end{array}\right]=\left[\begin{array}{llll}
\boldsymbol{e}^{T} & 1 & 1 & 1
\end{array}\right] \quad \text { (Price Indices) }
$$

The empirical matrix of structural coefficients in Eq. 10 is non-negative, column stochastic and - as has been verified when carrying out the empirical computations — irreducible for all 60 countries and years (covering the 2005-2015 period) considered. Thus, its transpose defines the empirical transition probability matrix $\boldsymbol{P}$ of a Markov chain for a closed Input-Output system:

$$
\boldsymbol{P}=\left[\begin{array}{cccc}
\boldsymbol{A}^{T} & \boldsymbol{a}_{m} & \boldsymbol{a}_{w} & \boldsymbol{a}_{s} \\
\boldsymbol{a}_{z}^{T} & 0 & a_{\tau}^{z} & 0 \\
\boldsymbol{a}_{c}^{T} & a_{m}^{c} & a_{\tau}^{c} & 0 \\
\boldsymbol{a}_{k}^{T} & a_{m}^{k} & a_{\tau}^{k} & 0
\end{array}\right] \quad \text { (Empirical transition probability matrix) }
$$

Every state of transition matrix $\boldsymbol{P}$ corresponds to an economic sector of the economy (intermediate or final), whereas each cell represents the probability that sector $i$ pays to sector $j$, in exchange for inputs to carry out its production. Complementing the interpretation of transition probabilities given in Section 2, there is a nuanced richness of extending the specification of the Markov chain to three final sectors. Crucially, each of them will have a greater weight in the economy than (almost) any intermediate industry on its own. Therefore, cross-country differences in the incomeexpenditure connection of imports with exports, wages-cum-taxes with consumption or profits with investment, may hint at specific structural features of the process of economic development.

If we consider the foreign sector ( $991 \mathrm{XM})$, high transition probabilities across the 'imports' column would indicate that industries, final consumers and firms heavily rely on imports to carry out production. But once a random monetary unit circulating in the economy reaches an import requirement, it will become a unit of exports in the following iteration of the chance process. And the more diversified the export structure of a country is, the easier it will be to reach other industries. Hence, in a small open economy with very high import transition probabilities but a very concentrated export basket, sectors may keep getting into the foreign sector, but there are very few options to traverse from the foreign sector to other nodes of the network. On the contrary, in a large country with relatively lower import propensities and a very diversified export basket, the random walker is less likely to reach the foreign sector but, once it has, there are more options to traverse to other industries through exports. 
This connection between imports and exports is particularly relevant in a context of international fragmentation of production (Hummels et al. 2001). An increase in the import content of exports which originates in higher intermediate import requirements $-\boldsymbol{a}_{m}^{T}$ in Eq. 10 - implies, ceteris paribus, a higher probability that the random walker traverses to imports, potentially reducing the betweenness centrality of domestic industries. In many cases, imported inputs are re-exported without any added domestic value. A possible way to account for this leakage from the domestic economy would be to add an 'import per unit of exports' coefficient in the intersection between the 'imports' row and the 'exports' column. But while "re-exports and re-imports" are present in the OECD-IOTs database methodology, almost no country reports this disaggregation. ${ }^{11} \mathrm{~A}$ direction for further research to fully take into account inter-country input linkages would be to extend our framework to a global Markov chain (Piccardi et al. 2018).

A similar reasoning to that of the foreign sector may be applied to the connection between profits and investment (993PI). High profit margins concentrated in a restricted set of industries (i.e. high transition probabilities in the 'profits' column), imply that the economy might be highly dependant on few activities to trigger investment demand in the next iteration. Instead, a diversified set of lower profit margins may redistribute purchasing power across industries to activate investment. However, if the sectoral composition of investment is highly concentrated towards few products (such as construction during a speculative housing bubble), whenever the random walker reaches the profit component of costs, traversing to construction will be highly likely in the next iteration (when profits become investment). And if the economy keeps traversing through very similar paths, other industries in the economy might be very difficult to reach, increasing the length of walks on the I-O graph.

Finally, an analogous interpretation may be given to the connection between wages-cum-taxes and consumption. A Markov chain approach to analysing a closed Input-Output system evinces the crucial relevance of the compositional structure of final consumption. This is because the wages-cum-taxes income component will generally be the highest transition probability in most industries across countries. But once the random walker has reached the Household and Government node, it will need to traverse to other vertices through final consumption. Thus, the consumption coefficients crucially redistribute the bulk of monetary circulation between industries.

Having obtained yearly series (for the period 2005-2015) of transition probability matrices $\boldsymbol{P}=\left[p_{i j}\right]$ (each of dimension $35 \times 35$ ) for 60 countries, for each of them we first computed its vector of stationary probabilities $\pi=\left[\pi_{i}\right]$. Then, we derived the associated asymmetric Laplacian matrix $\boldsymbol{L}=\widehat{\boldsymbol{\pi}}(\boldsymbol{I}-\boldsymbol{P})$ and computed its MoorePenrose inverse $\boldsymbol{M}=\left[m_{i j}\right]$. $^{12}$

\footnotetext{
${ }^{11}$ As documented in Timmer (2012, pp. 20-1), countries widely differ in their treatment of processing trade (i.e. re-imports/re-exports) within their national accounts.

${ }^{12}$ The Moore-Penrose generalised inverse is obtained by applying the Singular Value Decomposition (SVD) to matrix $\boldsymbol{L}$ with the R programming language function ginv of package MASS. For implementation details, please see Venables and Ripley (1999, p. 100).
} 
We extracted the main diagonal of $\boldsymbol{M}$, containing coefficients $m_{k k}$ in Eq. 2, each representing the extra distance traversed between two sectors when forced to pass through sector $k$. Each of these coefficients captures the (reciprocal) betweenness centrality of industry $k$, allowing us to compare sectoral vulnerabilities across countries and through time. Our empirical strategy consisted in: (i) assess the (cross-country) time trend of the ranking of sectoral vulnerabilities, (ii) illustrate (time-averaged) country differences in their sectoral vulnerabilities, and (iii) perform a clustering exercise to agglomerate countries based on the similarity of their sectoral rankings, devising a country typology of structural vulnerabilities across the globe.

\subsection{Generalised Structural Change Takes Time}

The first dimension we consider emphasises the time evolution of the ranking of sectoral vulnerabilities. We compute the median (rather than the average) of $m_{j j}$ across countries for each sector $j$, to avoid outliers biasing the results. Table 3 reports levels of $m_{j j}$ for selected years, the time-average, absolute difference and proportional rate of change between 2005 and 2015. On the left panel of the table, sectors are ordered by their position in the industry classification, i.e. primary, manufacturing and service industries (from 01T003AGR to 90T0980TS), followed by the three final sectors: foreign trade, households/government and profits/investment (991XM, 992YC and 993 PI, respectively). On the right panel of the table, a plot depicts the transitions in the sectoral ranking through time, sectors being displayed in increasing order of $m_{j j}$, i.e. in decreasing order of betweenness centrality.

From the right panel of the table it emerges that structural change takes time: for the first, most central 17 (out of 35) sectors, there are only two temporary and one permanent (adjacent) switchovers in ranking positions. That is, for the median economic system, the relative position of key sectoral vulnerabilities persists through time. As expected, the three final sectors have the smallest extra distance associated to the paths traversed between any two other industries. This is due to the high share of imports, wages-cum-taxes and profits in the unit cost structure of production activities.

Besides final sectors, industries with persistently high betweenness centrality across countries and through time belong to either: (i) the final consumption core of the economy, comprising food (10T12FOD, 01T03AGR), housing (41T43 CON, 68REA), government services (84GOV), health (86T88HTH) and education ( $85 \mathrm{EDU})$, or (ii) the infrastructure core of the economy, comprising trade (45T47WRT), KIBS (69T82OBZ), ${ }^{13}$ logistics (49T53TRN), energy (35T39EGW, $19 \mathrm{~T} 21 \mathrm{PECH})$ and financial intermediation (64T66FIN).

On the contrary, activities in the lower half of the ranking evince changes in their relative position between 2005 and 2015. Some variations are temporary, e.g. the motor vehicle industry (29MTR) and some of its key inputs (22RBP), probably triggered by the global financial crisis unfolding during 2009. However, some

\footnotetext{
${ }^{13}$ The 'KIBS' acronym stands for: Knowledge Intensive Business Services.
} 
Table 3 Extra distance traversed between two sectors when forced to pass through sector $j$ (in number of sectoral transitions)

Indicator $m_{j j}$ from Eq. 2; median across 60 countries; sectoral descriptors in Appendix C, Table 7

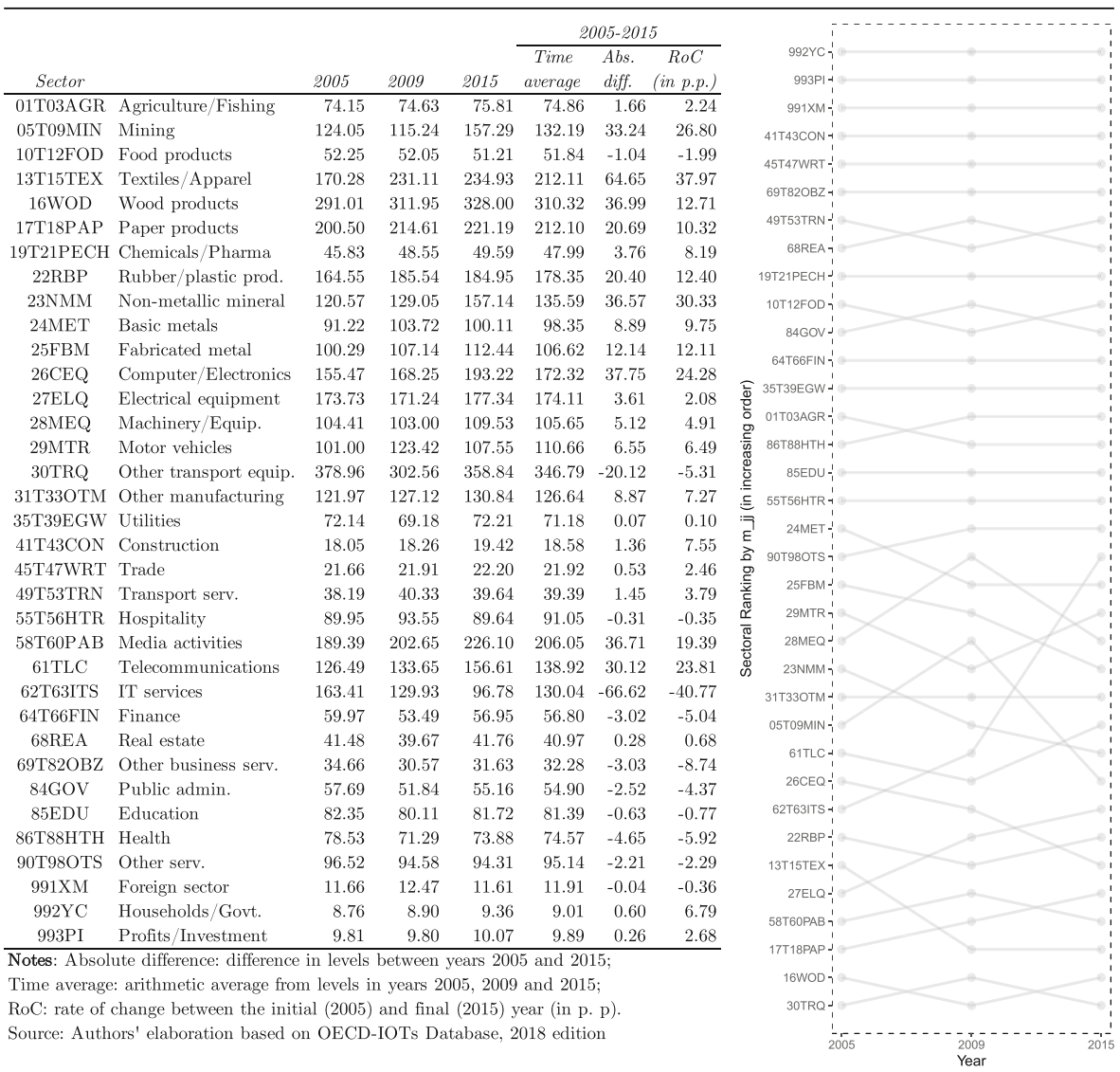

trajectories identify persistent structural changes across countries, e.g. the increasingly relevant intermediary role of Information Technology (IT, hereinafter) services (62T63ITS) in contrast to the decreasing role of textiles and apparel (13T15TEX).

Higher volatility of positions in the lower half of the ranking may be explained by, at least, two factors. Firstly, productive techniques are expected to change at a faster pace than essential consumption needs and core productive infrastructure. For example, while the content of mild steel in cars is projected to decrease (reducing the relative position of $24 \mathrm{MET}$ ), transportation and mobility services (19T53TRN) still remain crucial. Secondly, position changes may be reflecting processes of international fragmentation of production across countries. This is because the ranking depicts the betweenness centrality of domestic output by industries. To see this, consider the example of textiles and apparel (13T15TEX), in which several European countries have outsourced industry segments to selected Asian economies. By 
(A) Central tendency

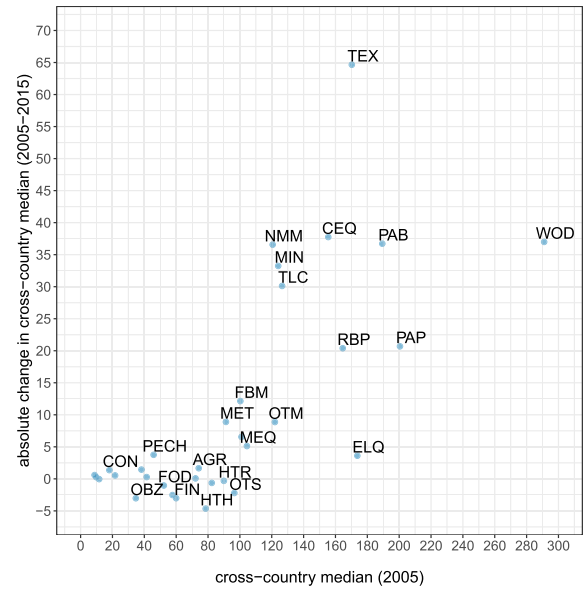

(B) Spread

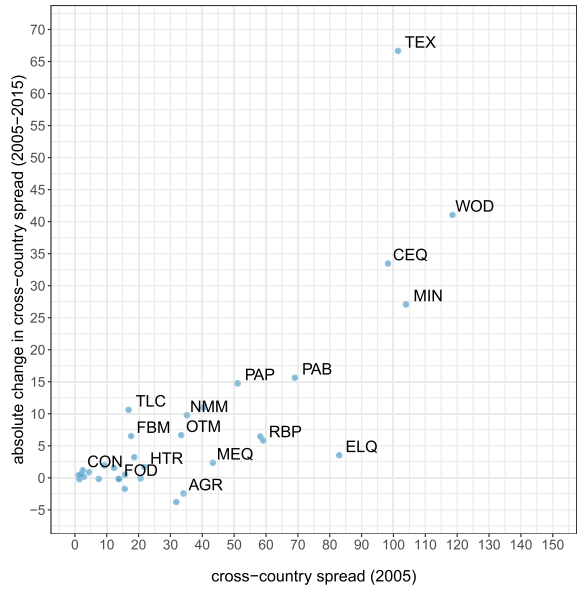

Fig. 2 Central tendency (Median) and spread (MAD) across countries of $m_{j j}$ for each sector $j$ (MAD: median absolute deviation). Due to their extreme values, industries $62 \mathrm{~T} 63$ ITS and $30 \mathrm{TRQ}$ are not displayed, but considered in the analysis of results. Full description of industry codes is available in Table 7 of Appendix C. Source: Authors' elaboration based on OECD-IOTs Database, 2018 edition

increasingly relying on imports to satisfy textile input requirements or final products, the likelihood with which other sectors traverse to the domestic textile industry is reduced. Hence, when forcing the path between any two sectors through industry $13 \mathrm{~T} 15 \mathrm{TEX}$, the extra distance travelled is likely to have increased, reducing the betweenness centrality of the industry.

Levels of $m_{j j}$ indicate the extra number of sectoral transitions in the path between any two sectors forced to traverse through node $j$. Therefore, a reduction in the level of $m_{j j}$ corresponds to an increase in the betweenness centrality of node $j$. Inspection of the left panel of Table 3 suggests that, between 2005 and 2015, highest increases in $m_{j j}$ concentrated around selected primary and manufacturing industries, whereas decreases mostly involved service activities. To better understand this pattern of changes, Fig. 2 depicts initial levels ( $x$-axis) and dynamics ( $y$-axis) of the central tendency and spread of $m_{j j}$, for each sector $j$.

Panel (A) in Fig. 2 evinces that less central sectors in 2005 became more peripheral by 2015 . That is, for sectors with initially high betweenness centrality (i.e. closer to the origin of the $x$-axis), the absolute change in centrality between 2005 and 2015 has been contained. From Panel (B) it emerges that sectors with a more dispersed cross-country level of $m_{j j}$ in 2005 (i.e. further away from the origin of the $x$-axis), experienced a sharper increase in dispersion between 2005 and 2015. ${ }^{14}$ Thus, the general pattern suggested is that central sectors become more central across most countries, whereas peripheral sectors became even more remote but to an uneven

\footnotetext{
${ }^{14}$ In correspondence with adopting the median as the measure of central tendency, we computed the median absolute deviation (MAD) across countries (index $r$ ) for each sector $j$, i.e. $\mathrm{MAD}_{j}=$ $\sum_{r} \operatorname{median}\left(\left|m_{j j}^{r}-\tilde{m}_{j j}\right|\right)$, where $\tilde{m}_{j j}=\operatorname{median}\left(m_{j j}^{r}\right)$.
} 
extent depending on the country considered. In a nutshell, between 2005 and 2015, the cross-country evolution of sectoral vulnerabilities has experienced a phenomenon of 'convergence at the top, divergence at the bottom' of the betweenness centrality scale.

It would be interesting to compare the sectoral ranking emerging from Table 3 with more traditional I-O indicators, such as simple output multipliers (Miller and Blair 2009, p. 246) and even a sector's gross output $-x_{j}$ in Eq. 9. The results of such comparison are reported in Appendix B, and allow to contextualise and highlight the additional circularity captured by a fully closed I-O scheme.

\subsection{Countries are Structurally Different}

While the upper-half of the ranking of sectoral vulnerabilities for the cross-country median (reported in the right panel of Table 3) may show persistence and contained changes in dispersion, differences between individual economies are still pervasive. Interpreting such differences may lead to a qualitative understanding of the relationship between country-specific aspects of the productive structure and changing sectoral vulnerabilities along a development path.

To illustrate this, Table 4 reports (time-averaged) country differences in sectoral vulnerabilities - as measured by $m_{j j}$ - for China, the median world economy and the United States. The right-panel of the table depicts the transitions in the sectoral ranking of vulnerabilities between these three economies. We have highlighted industries whose ranking position experiences a sharp change in direction, both when transitioning from China to the median world economy, as well as from the latter to the USA.

Given that China is, by several metrics, the key emerging economy in the period considered, whereas the United States is still the advanced industrial economy with highest share in global income, ranking transitions exemplify the changing role of sectoral vulnerabilities along (possible) paths of economic growth.

While the households/government (992YC) and profits/investment (993PI) final sectors remain crucial across countries, the foreign sector (991XM) becomes less central for the US than it is for China and the median world economy. Intuitively, industry cost structures in larger advanced industrial economies tend to be relatively less dependent on foreign inputs. However, given the extent of its involvement across inter-country value chains and its developmental stage, the foreign sector is still the third source of vulnerability for China.

Sectors with a sharp decrease in their relevance as intermediary nodes when transitioning from China to the US (and through the median world economy) comprise, first and foremost, agricultural and food processed products (01T03AGR, $10 \mathrm{~T} 12 \mathrm{FOD})$. This evinces the ongoing process of population and labour force expansion in the Chinese economy. A similar point could be made about textiles and wearing apparel (13T15TEX), though this may also be linked to China's role in global value chains (GVCs) for these products. Finally, the case of basic metals and mechanical machinery equipment ( $24 \mathrm{MET}$ and $28 \mathrm{MEQ}$, respectively) evinces the ongoing process of expanding industrialisation in China, with respect to the US and the median world economy. 
Table 4 Extra distance traversed between two sectors when forced to pass through sector $j$ (in number of sectoral transitions)

Indicator $m_{j j}$ from Eq. 2; countries: China (CHN), World median (WLD) and the United States (USA); time average for years 2005, 2009 and 2015; sectoral descriptors in Appendix C, Table 7

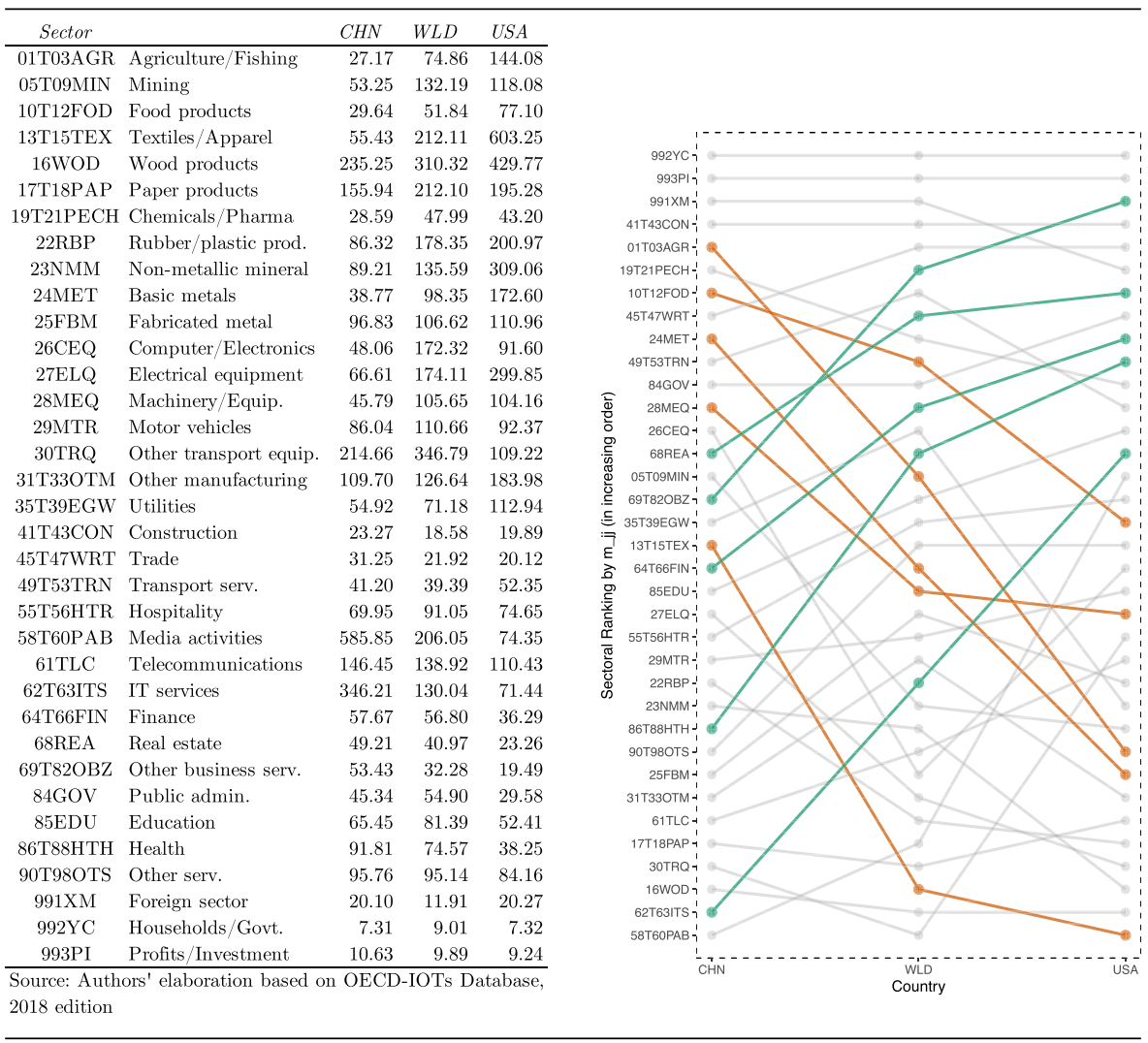

Instead, the increasing betweenness centrality of (knowledge-intensive) business services in the USA (69T82OBZ) - being the third most relevant sector - illustrates the prominence of its 'service economy'. Moreover, the US technological leadership may be perceived by the high relative ranking position of IT services (62T63ITS). This process of ever-increasing centrality of service sectors includes technologically advanced personal services $(86 \mathrm{~T} 88 \mathrm{HTH})$ but also activities leveraging the financialisation process of the US economy (68REA, 64T66FIN). Such a high concentration of node vulnerabilities in employment-intensive service sectors, alerts on the high potential impact of a shock to the US labour force.

\subsection{Structural Vulnerabilities: A Typology}

The comparison between China and the USA evinced contrasting sectoral vulnerabilities between them, as well as with respect to the median world economy. 
Therefore, to make sense of cross-country differences in node vulnerabilities, we report the results of a clustering exercise in which we agglomerate countries based on the similarity of their sectoral rankings, devising a country typology of structural vulnerabilities across the globe.

In particular, we departed from a sector $\times$ country matrix of the (time-averaged) values for $m_{j j}$ and converted each column into a ranking of node vulnerabilities. Then, we computed the Spearman rank correlation between each pair of columns and articulated all (bilateral) correlation coefficients into a resulting symmetric (country $\times$ country) similarity matrix $S=\left[s_{i j}\right]$. The similarity matrix was then converted into a dissimilarity matrix, by computing: $d_{i j}=\sqrt{2 \times\left(1-s_{i j}\right)}$, and a hierarchical clustering analysis (using the complete agglomeration method) was performed, obtaining the dendrogram displayed in Fig. 3.

As a heuristic device, we articulated results of the cluster analysis into 6 groups (G01 to G06 in Fig. 3). We provide a qualitative characterisation of each group based on the ranking of node vulnerabilities across countries within each country set, reported in Table 5.

In counter-clockwise order, group G01 comprises mainly China and South East Asian countries (with the exception of MEX and TUN). Economies of 'factory Asia'

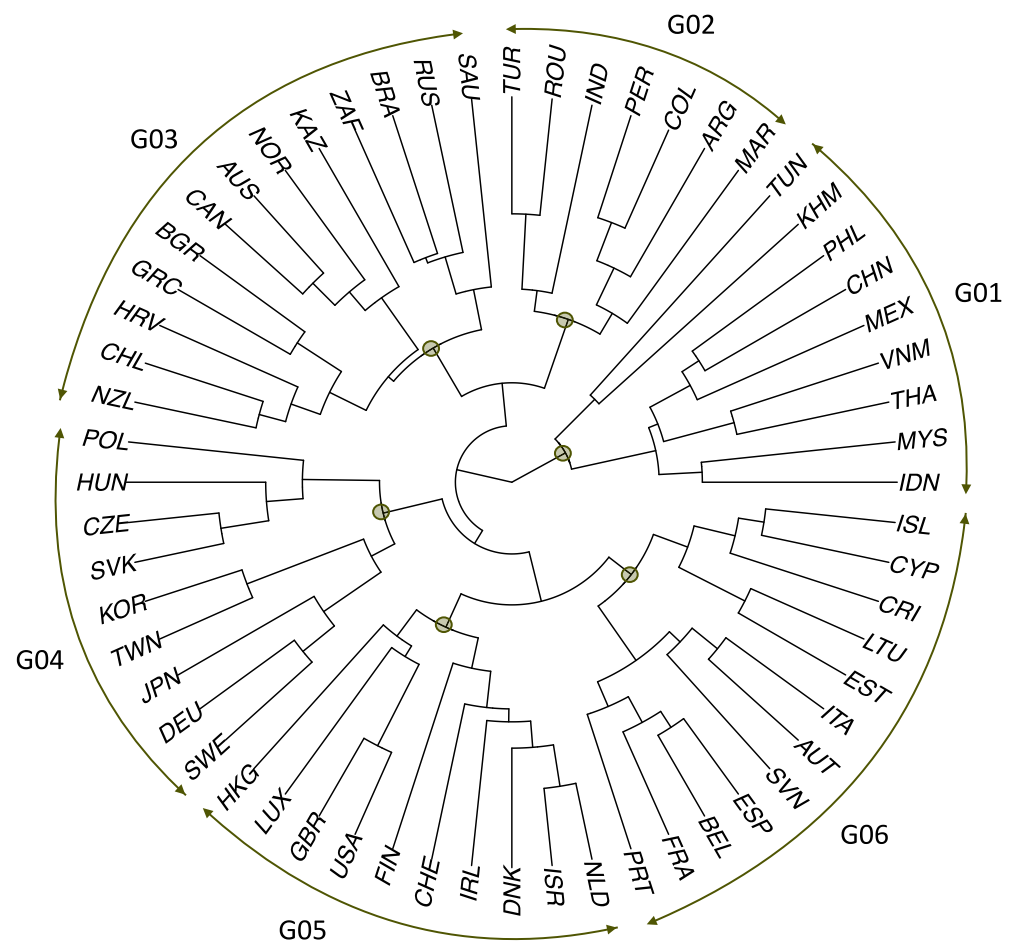

Fig. 3 Hierarchical clustering of countries according to the relative distance in their sectoral rankings for $m_{j j}$. (Indicator $m_{j j}$ from Eq. 2; Clustering agglomeration method: complete; 60 countries; averaged through time for years 2005, 2009 and 2015; country descriptors in Appendix C, Table 6). Source: Authors' elaboration based on OECD-IOTs Database, 2018 edition 
Table 5 Extra distance traversed between two sectors when forced to pass through sector $j$ (in number of sectoral transitions)

Indicator $m_{j j}$ from Eq. 2; median across countries within each group: G01-G06, detailed in Fig. 3; averaged through time for years 2005, 2009 and 2015; sectoral descriptors in Appendix C, Table 7

\begin{tabular}{|c|c|c|c|c|c|c|c|c|c|c|c|}
\hline Sector & G01 & Sector & G02 & Sector & G03 & Sector & G04 & Sector & G05 & Sector & G06 \\
\hline 993PI & $\overline{8.54}$ & $993 \mathrm{PI}$ & $\overline{8.53}$ & $992 \mathrm{YC}$ & $\overline{8.93}$ & $992 \mathrm{YC}$ & $\overline{8.76}$ & $992 \mathrm{YC}$ & 8.72 & $992 \mathrm{YC}$ & 8.98 \\
\hline $991 \mathrm{XM}$ & 10.14 & $992 \mathrm{YC}$ & 10.07 & $993 \mathrm{PI}$ & 9.78 & $993 \mathrm{PI}$ & 9.73 & $993 \mathrm{PI}$ & 11.84 & $993 \mathrm{PI}$ & 11.48 \\
\hline $992 \mathrm{YC}$ & 10.49 & $41 \mathrm{~T} 43 \mathrm{CON}$ & 13.85 & $991 \mathrm{XM}$ & 13.63 & $991 \mathrm{XM}$ & 10.04 & $991 X M$ & 11.91 & $991 X M$ & 11.97 \\
\hline $41 \mathrm{~T} 43 \mathrm{CON}$ & 21.26 & $991 \mathrm{XM}$ & 13.88 & $41 \mathrm{~T} 43 \mathrm{CON}$ & 16.55 & $41 \mathrm{~T} 43 \mathrm{CON}$ & 18.97 & $41 \mathrm{~T} 43 \mathrm{CON}$ & 21.17 & $41 \mathrm{~T} 43 \mathrm{CON}$ & 19.39 \\
\hline 45T47WRT & 25.61 & 45T47WRT & 22.30 & 45T47WRT & 20.69 & 45T47WRT & 22.70 & 45T47WRT & 21.89 & 45T47WRT & 20.61 \\
\hline 01T03AGR & 29.23 & 49T53TRN & 38.64 & $69 \mathrm{~T} 82 \mathrm{OBZ}$ & 30.04 & $69 \mathrm{~T} 82 \mathrm{OBZ}$ & 31.32 & $69 \mathrm{~T} 82 \mathrm{OBZ}$ & 27.60 & $69 \mathrm{~T} 82 \mathrm{OBZ}$ & 29.92 \\
\hline 10T12FOD & 31.47 & $69 \mathrm{~T} 82 \mathrm{OBZ}$ & 40.48 & 05T09MIN & 30.31 & 68REA & 39.27 & 68REA & 31.88 & 49T53TRN & 37.87 \\
\hline $19 \mathrm{~T} 21 \mathrm{PECH}$ & 38.33 & $10 \mathrm{~T} 12 \mathrm{FOD}$ & 41.07 & $49 \mathrm{~T} 53 \mathrm{TRN}$ & 36.38 & 49T53TRN & 40.26 & 64T66FIN & 35.30 & 68REA & 38.88 \\
\hline 49T53TRN & 42.59 & 01T03AGR & 42.37 & $68 \mathrm{REA}$ & 39.15 & 19T21PECH & 47.85 & 49T53TRN & 43.37 & 10T12FOD & 51.66 \\
\hline 05T09MIN & 44.31 & 05T09MIN & 42.47 & $84 \mathrm{GOV}$ & 47.00 & 29MTR & 48.05 & $84 \mathrm{GOV}$ & 43.40 & 64T66FIN & 51.74 \\
\hline $26 \mathrm{CEQ}$ & 48.06 & $19 \mathrm{~T} 21 \mathrm{PECH}$ & 45.44 & 19T21PECH & 50.34 & $84 \mathrm{GOV}$ & 49.19 & $86 \mathrm{~T} 88 \mathrm{HTH}$ & 45.55 & $86 \mathrm{~T} 88 \mathrm{HTH}$ & 53.78 \\
\hline 13T15TEX & 61.75 & 68REA & 47.34 & 64T66FIN & 52.24 & $28 \mathrm{MEQ}$ & 56.08 & 19T21PECH & 47.24 & $84 \mathrm{GOV}$ & 54.19 \\
\hline $55 \mathrm{~T} 56 \mathrm{HTR}$ & 69.95 & $24 \mathrm{MET}$ & 51.49 & $10 \mathrm{~T} 12 \mathrm{FOD}$ & 56.58 & $26 \mathrm{CEQ}$ & 59.54 & $85 \mathrm{EDU}$ & 62.60 & 19T21PECH & 56.91 \\
\hline 64T66FIN & 73.48 & 35T39EGW & 72.63 & 01T03AGR & 66.50 & 64T66FIN & 60.25 & 10T12FOD & 69.35 & 35T39EGW & 59.03 \\
\hline 29MTR & 81.59 & 84GOV & 74.68 & 35T39EGW & 74.09 & 35T39EGW & 61.15 & 62T63ITS & 73.13 & $85 \mathrm{EDU}$ & 65.55 \\
\hline 68REA & 84.68 & 29MTR & 75.05 & $85 \mathrm{EDU}$ & 81.11 & 10T12FOD & 70.25 & 90T98OTS & 80.30 & $55 \mathrm{~T} 56 \mathrm{HTR}$ & 69.93 \\
\hline $27 \mathrm{ELQ}$ & 91.31 & $23 \mathrm{NMM}$ & 78.12 & $86 \mathrm{~T} 88 \mathrm{HTH}$ & 83.70 & $25 \mathrm{FBM}$ & 72.71 & 35T39EGW & 82.04 & 01T03AGR & 88.37 \\
\hline $22 \mathrm{RBP}$ & 92.23 & 13T15TEX & 80.38 & 90T98OTS & 83.90 & $86 \mathrm{~T} 88 \mathrm{HTH}$ & 74.83 & $26 \mathrm{CEQ}$ & 83.47 & 90T98OTS & 95.08 \\
\hline 35T39EGW & 98.29 & 64T66FIN & 80.60 & $24 \mathrm{MET}$ & 87.93 & $85 \mathrm{EDU}$ & 82.38 & $28 \mathrm{MEQ}$ & 99.63 & $25 \mathrm{FBM}$ & 97.16 \\
\hline $24 \mathrm{MET}$ & 100.68 & $55 \mathrm{~T} 56 \mathrm{HTR}$ & 83.28 & $55 \mathrm{~T} 56 \mathrm{HTR}$ & 94.09 & 90T980TS & 85.23 & $55 \mathrm{~T} 56 \mathrm{HTR}$ & 101.54 & 31T330TM & 97.40 \\
\hline 90T98OTS & 101.70 & $85 \mathrm{EDU}$ & 97.95 & $25 \mathrm{FBM}$ & 113.67 & 24MET & 87.15 & $25 \mathrm{FBM}$ & 124.84 & 29MTR & 100.15 \\
\hline 23NMM & 107.35 & $86 \mathrm{~T} 88 \mathrm{HTH}$ & 98.70 & 61TLC & 128.89 & 27ELQ & 99.08 & $58 \mathrm{~T} 60 \mathrm{PAB}$ & 135.74 & 62T63ITS & 126.78 \\
\hline $28 \mathrm{MEQ}$ & 108.64 & $25 \mathrm{FBM}$ & 99.92 & $28 \mathrm{MEQ}$ & 129.38 & 01T03AGR & 102.57 & 61TLC & 140.20 & $61 \mathrm{TLC}$ & 132.45 \\
\hline $25 \mathrm{FBM}$ & 114.65 & 28MEQ & 109.47 & $23 \mathrm{NMM}$ & 129.70 & 62T63ITS & 104.02 & 31T33OTM & 140.67 & $23 \mathrm{NMM}$ & 141.34 \\
\hline $69 \mathrm{~T} 82 \mathrm{OBZ}$ & 120.06 & 90T98OTS & 111.17 & 62T63ITS & 165.91 & $55 \mathrm{~T} 56 \mathrm{HTR}$ & 110.37 & 01T03AGR & 148.23 & $24 \mathrm{MET}$ & 149.45 \\
\hline $84 \mathrm{GOV}$ & 123.18 & $27 \mathrm{ELQ}$ & 111.40 & $58 \mathrm{~T} 60 \mathrm{PAB}$ & 188.53 & $22 \mathrm{RBP}$ & 111.59 & 05T09MIN & 264.79 & $28 \mathrm{MEQ}$ & 158.67 \\
\hline 31T33ОTM & 126.36 & 31T330TM & 111.85 & 31T33OTM & 188.74 & 31T33OTM & 138.95 & 23NMM & 273.78 & $22 \mathrm{RBP}$ & 183.64 \\
\hline $61 \mathrm{TLC}$ & 146.45 & $22 \mathrm{RBP}$ & 139.42 & $22 \mathrm{RBP}$ & 228.36 & 23NMM & 139.57 & $22 \mathrm{RBP}$ & 275.56 & 17T18PAP & 192.93 \\
\hline $85 \mathrm{EDU}$ & 159.35 & $61 \mathrm{TLC}$ & 147.24 & $17 \mathrm{~T} 18 \mathrm{PAP}$ & 238.86 & 61TLC & 142.62 & 24MET & 284.94 & $27 \mathrm{ELQ}$ & 194.46 \\
\hline $86 \mathrm{~T} 88 \mathrm{HTH}$ & 211.72 & $26 \mathrm{CEQ}$ & 222.19 & $27 \mathrm{ELQ}$ & 297.10 & $58 \mathrm{~T} 60 \mathrm{PAB}$ & 172.95 & 17T18PAP & 285.00 & $58 \mathrm{~T} 60 \mathrm{PAB}$ & 208.28 \\
\hline $30 \mathrm{TRQ}$ & 215.64 & 17T18PAP & 233.86 & $16 \mathrm{WOD}$ & 302.57 & 17T18PAP & 183.36 & $27 \mathrm{ELQ}$ & 310.38 & 13T15TEX & 217.64 \\
\hline 17T18PAP & 216.17 & 62T63ITS & 261.87 & $26 \mathrm{CEQ}$ & 365.02 & 13T15TEX & 227.60 & 29MTR & 353.67 & $26 \mathrm{CEQ}$ & 227.30 \\
\hline 16WOD & 235.25 & $16 \mathrm{WOD}$ & 332.14 & 13T15TEX & 387.39 & $30 \mathrm{TRQ}$ & 271.16 & $30 \mathrm{TRQ}$ & 468.63 & $16 \mathrm{WOD}$ & 301.32 \\
\hline $58 \mathrm{~T} 60 \mathrm{PAB}$ & 352.43 & $58 \mathrm{~T} 60 \mathrm{PAB}$ & 375.32 & $30 \mathrm{TRQ}$ & 407.34 & 16WOD & 336.17 & $16 \mathrm{WOD}$ & 517.32 & 05T09MIN & 435,81 \\
\hline 62T63ITS & 439.32 & $30 \mathrm{TRQ}$ & 616.57 & 29MTR & 660.24 & 05T09MIN & 478.64 & 13T15TEX & 563.67 & $30 \mathrm{TRQ}$ & 939.94 \\
\hline
\end{tabular}

Source: Authors' elaboration based on OECD-IOTs Database, 2018 edition

evince high inter-country trade integration, as can be seen from the high vulnerability associated to the foreign trade sector (991XM), as well as industries which articulate key global value chains, such as wearing apparel (13T15TEX) and computing equipment (26CEQ). Being a group of fast growing, emerging countries, their developmental stage is characterised by an expanding population (01T03AGR, $10 \mathrm{~T} 12 \mathrm{FOD}$ ) and natural resource exploitation (05T09MIN, 19T21PECH).

Countries of group G02 are (mostly) middle-income economies of South America, the Black Sea area, India and Morocco. The important intermediary role of the construction sector ( $41 \mathrm{~T} 43 \mathrm{CON})$ should be highlighted, as well as the extremely low ranking positions of high-tech industries (26CEQ, 62T63ITS), suggesting these economies are far from the technological frontier.

The characterising feature of the third group (G03) is that it consists of naturalresource based economies. This is evinced by the relatively high vulnerability of mining and refined petroleum (05T09MIN, 19T21PECH), agricultural activities (01T03AGR) and food processing (10T12FOD). Countries at different development stages are further distinguished within the group: emerging (SAU, RUS, BRA, ZAF) 
and advanced (NOR, AUS, CAN) economies with a high reliance on mining resources agglomerate into different sub-clusters.

Instead, for countries of group G04, mining is the least central activity of their domestic productive structure. This group represents a core set of manufacturingintensive economies comprising advanced East Asian countries, Sweden, Germany and its associated (through strong value chain linkages) Central and Eastern European countries. Heavy industry and high-tech manufacturing sectors feature prominently among node vulnerabilities: motor vehicles (29MTR), mechanical machinery (2 8MEQ), computing equipment (26 CEQ) and fabricated metal products (25FBM).

Countries in group G05 may be described as advanced service economies: it comprises the USA, the UK and high-income small open economies featuring the prominence of knowledge-intensive (69T82OBZ) and financial (68REA, $64 \mathrm{~T} 66 \mathrm{FIN})$ services, but also a higher relative betweenness centrality of high-tech industries (62T63ITS, 26 CEQ).

Finally, group G06 includes a set of European countries (with the exception of CRI) featuring (relatively) high node vulnerabilities in the service infrastructure of the economy (e.g. 69T82OBZ, 49T53TRN, 68REA, 64T66FIN), but also in traditional manufacturing sectors (10T12FOD), and further away from the technological frontier (62T63 ITS, 26CEQ) than countries of group G05.

Overall, results from the cluster analysis suggest a country typology with differentiated structural profiles. At the risk of oversimplifying, clusters depict emerging economies undergoing fast-paced structural transformation (G01), an array of natural-resource based economies (G03), a high-tech manufacturing core (G04), a high-tech services core (G05), and high-income European (G06) / middle-income peripheral (G02) countries with varying degrees of distance from the technological frontier. A direction for further research would be to study the inter-country trade complementarities between these clusters.

\section{Summary of Findings and Concluding Remarks}

Input-Output (I-O, hereinafter) analyses of structural vulnerabilities are generally performed using the open I-O model (Galbusera and Giannopoulos 2018). Instead, a key contribution of this paper has been to specify and empirically implement the precise mapping between a regular Markov chain and a closed Input-Output system, with multiple categories for the final sector.

Amongst different methods to assess I-O network resilience, identification of key sectors is frequently used (e.g. Kelly et al. 2016). But rather than focusing on traditional indicators (such as backward/forward linkages), we applied a notion of betweenness centrality in complex networks (Ranjan and Zhang 2013) to characterise sectoral vulnerabilities in national economies, evincing structural (dis)similarities.

Empirical findings suggest that, for the median economic system across the 60 countries considered, the relative position of key sectoral vulnerabilities persists through time. However, between 2005 and 2015, the cross-country evolution of relative vulnerabilities experienced a phenomenon of 'convergence at the top, divergence at the bottom' of the betweenness centrality scale. Moreover, a generalised feature of 
structural change has been the increasingly relevant intermediary role of Information Technology services.

Whilst persistence through time of the intermediary role for key network nodes has been observed, there are pervasive differences between individual economies. A comparison between China and the US reveals changing sectoral vulnerabilities along development paths, traversing from high vulnerability in agricultural and food processed products (in China) to a crucial role for business services (in the US).

Clustering economies - based on the similarity of their sectoral rankings suggests a country typology with differentiated structural profiles, highlighting the distinctions between emerging, industrialisation-intensive economies and natural resource-based countries, as well as between an advanced manufacturing core with respect to a high-tech services core of economies. Further research could study the inter-country trade complementarities between these clusters from a network perspective (Caschili et al. 2015).

In fact, a limitation emerging from these results is that our analysis is not framed in terms of a set of interdependent economies, articulated in an inter-country, global Markov chain (as in Piccardi et al. 2018). This notwithstanding, we acknowledge the relations each country has with the rest of the world through the 'foreign trade' sector.

Finally, an interesting direction for further research would be to simulate targeted attacks to each national (or a global) I-O network through the hypothetical extraction method (Dietzenbacher et al. 2019), iteratively measuring how the sectoral distribution of vulnerabilities changes as more central nodes are removed from the network. Such an approach may hint at economy-wide resilience, complementing the identification of local vulnerabilities.

\section{Appendix A: Relationship Between Network Centrality Indices}

Within the context of random walks on graphs, the notions of eigenvector (Friedkin 1991), closeness (Noh and Rieger 2004) and betweenness (Newman 2005) centrality are amongst the most widely used. Not only for abstract descriptions of network structure, but also when it comes to the analysis of economic, inter-industry flows (Blöchl et al. 2011).

In this appendix we formally relate the three centrality notions, in order to clarify how the betweenness centrality indicator for node $j, m_{j j}$, defined in Eq. 2, considers paths connecting all network nodes. To begin with, recall Eq. 1:

$$
H(i, j)=m_{j j}-m_{i j}+\sum_{l=1}^{n}\left(m_{i l}-m_{j l}\right) \pi_{l}
$$

Aggregating over $i$, we obtain:

$$
\sum_{i=1}^{n} H(i, j)=n \cdot m_{j j}-\sum_{i=1}^{n} m_{i j}+\sum_{l=1}^{n} \pi_{l} \sum_{i=1}^{n} m_{i l}-n \sum_{l=1}^{n} m_{j l} \pi_{l}
$$


But due to the properties of the Moore-Penrose inverse (Boley et al. 2011, p. 232), we have $\sum_{i=1}^{n} m_{i j}=\sum_{i=1}^{n} m_{i l}=0$, so we may write:

$$
m_{j j}=\frac{1}{n} \cdot \sum_{i=1}^{n} H(i, j)-\sum_{l=1}^{n} m_{j l} \pi_{l}
$$

Note that the first term of the right-hand side of Eq. 12:

$$
\operatorname{MFTP}(j)=\frac{1}{n} \cdot \sum_{i=1}^{n} H(i, j)
$$

represents the mean first passage time of target node $j$, i.e. the average number of state transitions needed to reach node $j$ for the first time, averaged across all possible source nodes, known as an indicator of closeness centrality for node $j$ (Blöchl et al. 2011, eq. (5)).

Hence, our betweenness centrality indicator $m_{j j}$ may be written as:

$$
m_{j j}=\operatorname{MFPT}(j)-\sum_{l=1}^{n} m_{j l} \pi_{l}
$$

i.e. it is a measure of closeness centrality, $\operatorname{MFPT}(j)$, corrected by a weighted average of industries' eigenvector centralities $\left(\pi_{l}\right)$, the weights being the corresponding elements of row $j$ of the Moore-Penrose inverse $\left(m_{j l}\right)$.

In this way, expression (14) renders explicit how our betweenness centrality indicator $m_{j j}$ is connected with the notions of closeness and eigenvector centrality, within the context of random walks on graphs.

\section{Appendix B: Comparison with Traditional Input-Output Indicators}

The interpretation of $m_{j j}$ in Eq. 2 as an indicator of betweenness centrality for a node in a closed Input-Output (I-O, hereinafter) system is, to our knowledge, novel. Hence, it would be useful to compare the (cross-country) sectoral ranking implied by this measure with traditional I-O measures of industry centrality. In particular, two such measures are considered, namely the simple output multiplier and gross output for industry $j$, respectively:

$$
\begin{aligned}
\text { output_mult_j } & =\boldsymbol{e}^{T}(\boldsymbol{I}-\boldsymbol{A})^{-1} \boldsymbol{e}_{j} \\
\text { go_j } & =x_{j}
\end{aligned}
$$

where $\boldsymbol{A}$ is the technical coefficients matrix defined in Eqs. $5-6, \boldsymbol{e}=[1 \ldots 1 \ldots 1]^{T}$ is a sum vector, and $\boldsymbol{e}_{j}=[0 \ldots 1 \ldots 0]^{T}$ is a column selector vector (with 1 in the $j$ th. position and zeros elsewhere).

The simple output multiplier measures the intensity of economy-wide backward linkages activated by final demand addressed to industry $j$. In this sense, "comparison of output multipliers would show where [an additional unit of final] spending would have the greatest impact in terms of total dollar value of output generated 
throughout the economy" (Miller and Blair 2009, p. 246). As such, it may be interpreted as an industry centrality indicator. However, being formulated within the logic of an open I-O model, it only considers network paths amongst industries, whilst $m_{j j}$ accounts also for network paths connecting final sectors. This conceptual difference is expected to generate a mismatch in centrality rankings, given the crucial influence of final sectors in structuring circularity.

A second comparison of interest is that with industry gross output $x_{j}$ which, within the network implied by system (9), represents a node's degree. Note that $x_{j}$ includes both inter-industry as well as final sector transactions.

Figure 4 reports the industry ranking comparison between alternative centrality indicators. To allow for comparability with Eq. 15, the analysis is restricted to the set of industries, i.e. excluding final sectors. The left panel depicts industry rankings for cross-country, time-averaged median values of each centrality indicator $\left(m_{-} j j, g o_{-} j\right.$ and output_mult_j), whereas the right panels of the figure depict the correlation between indicators for pooled country-level (time-averaged) data points.

Two main features emerge. First, there is a neat negative correlation between $m_{j j}$ and gross output of industry $j$, i.e. lower extra distance traversed indicating a higher betweenness centrality generally corresponds to a higher node degree. In fact, for the top 15 industries, there are only adjacent switchovers in ranking positions when moving from betweenness centrality $\left(m_{-} j j\right)$ to gross output $\left(g o_{-} j\right)$. Recall that these top industries correspond to the final consumption/infrastructure core of the economy identified from Table 3, and feature prominently in the industry composition of final sectors of the economy. Notably, though, the (log-scaled) scatter plot evinces that the negative relationship between these two indicators is subject to considerable variability. Hence, while an industry ranking based on gross output may be a good predictor of the relative ordering of top industries according to betweenness centrality, there are relevant non-linearities which our centrality indicator $m_{j j}$ is capturing, with respect to a node's degree. These non-linearities are particularly relevant when assessing local vulnerabilities across countries.

Second, the correlation between $m_{j j}$ and the simple output multiplier of industry $j$ is close to zero. As expected, the notorious leaps in ranking positions when moving from betweenness centrality $\left(m_{-} j j\right)$ to output multipliers (output_mult_j) evinces the contrast between a closed and an open I-O model, respectively. By not accounting for the circularity intertwining final sectors with intermediate industries, activities ranking high in terms of $m_{j j}$ may have relatively lower output multipliers (e.g. 45T4 7WRT, 69T82OBZ, 68REA, 84GOV, 85EDU). On the contrary, industries mostly producing (and intensively using) intermediate inputs may rank high in terms of output multipliers, but have relatively lower betweenness centrality (e.g. 23NMM, 22RBP, 58T60PAB, 17T18PAP, 16WOD). 

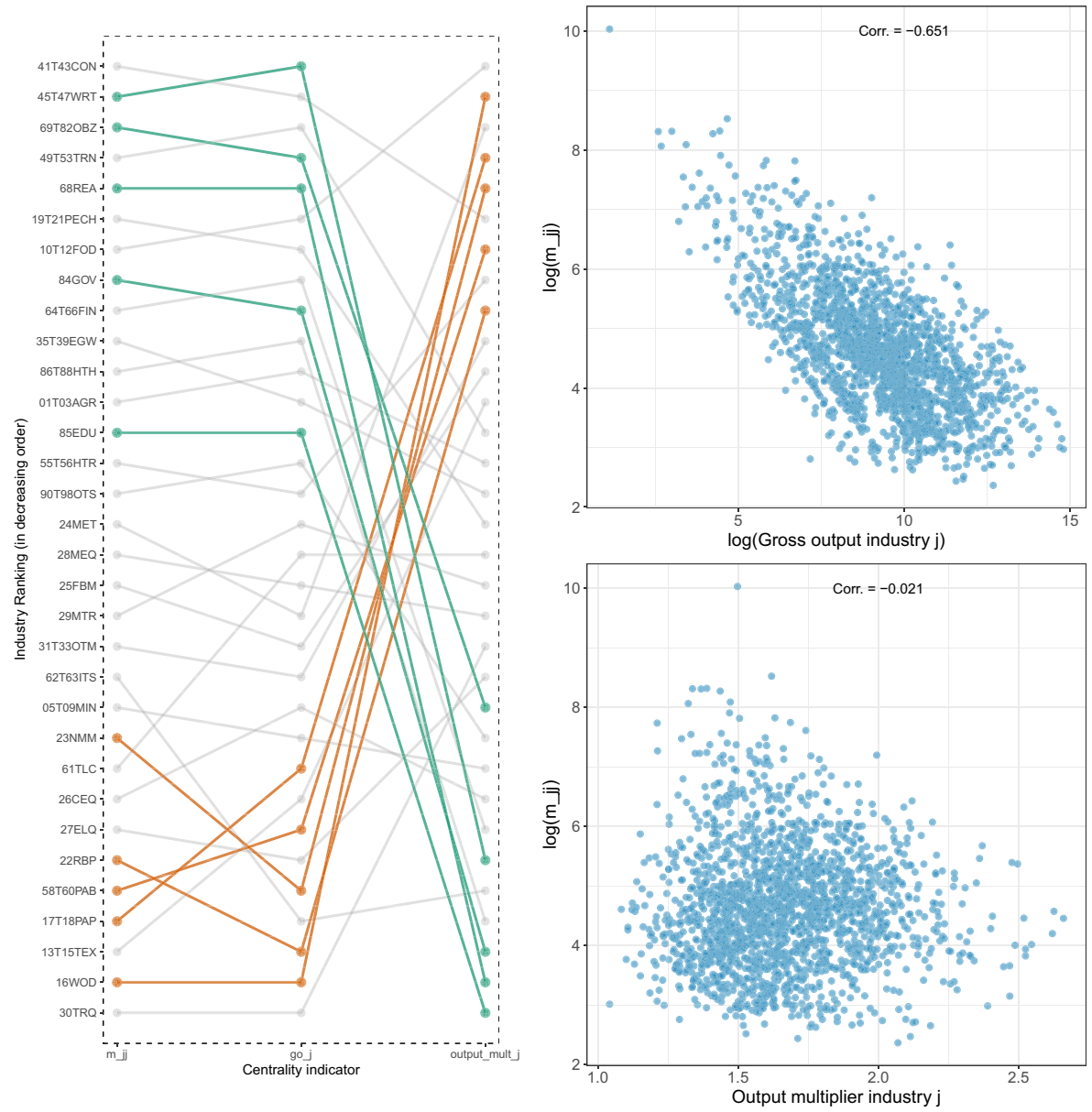

Fig. 4 Industry ranking comparison between $m_{j j}$, gross output and I-O output multiplier. (Indicator $m_{j j}$ - m_jj- from Eq. 2; Gross output - go_j - from Eq. 16; I-O output multiplier - output_mult_j - from Eq. 15; cross-country median averaged through time for years 2005, 2009 and 2015; sectoral descriptors in Appendix C, Table 7). Source: Authors' elaboration based on OECD-IOTs Database, 2018 edition. Notes: To facilitate interpretation, gross output and I-O output multipliers in the left panel have been multiplied by -1 , so that the logic of their industry ranking in decreasing order coincides with that of $m_{j j}$ 


\section{Appendix C: OECD Input-Output Tables Database: Country List and Industry Classification}

Table 6 OECD Input-Output Tables (IOTs) database country dictionary (List of 60 countries considered for the computations in the paper)

\begin{tabular}{|c|c|c|c|}
\hline ISO3 & Country & ISO3 & Country \\
\hline$\overline{\mathrm{ARG}}$ & Argentina & $\mathrm{ITA}$ & Italy \\
\hline AUS & Australia & JPN & Japan \\
\hline AUT & Austria & $\mathrm{KAZ}$ & Kazakhstan \\
\hline BEL & Belgium & KHM & Cambodia \\
\hline BGR & Bulgaria & KOR & Korea \\
\hline BRA & Brazil & LTU & Lithuania \\
\hline CAN & Canada & LUX & Luxembourg \\
\hline $\mathrm{CHE}$ & Switzerland & MAR & Morocco \\
\hline CHL & Chile & MEX & Mexico \\
\hline $\mathrm{CHN}$ & People's Rep. of China & MYS & Malaysia \\
\hline $\mathrm{COL}$ & Colombia & NLD & Netherlands \\
\hline CRI & Costa Rica & NOR & Norway \\
\hline CYP & Cyprus & NZL & New Zealand \\
\hline $\mathrm{CZE}$ & Czech Republic & PER & Peru \\
\hline $\mathrm{DEU}$ & Germany & PHL & Philippines \\
\hline DNK & Denmark & POL & Poland \\
\hline ESP & Spain & PRT & Portugal \\
\hline $\mathrm{EST}$ & Estonia & $\mathrm{ROU}$ & Romania \\
\hline FIN & Finland & RUS & Russian Federation \\
\hline FRA & France & SAU & Saudi Arabia \\
\hline GBR & United Kingdom & SVK & Slovak Republic \\
\hline GRC & Greece & $\mathrm{SVN}$ & Slovenia \\
\hline $\mathrm{HKG}$ & Hong Kong, China & SWE & Sweden \\
\hline HRV & Croatia & THA & Thailand \\
\hline HUN & Hungary & TUN & Tunisia \\
\hline IDN & Indonesia & TUR & Turkey \\
\hline IND & India & TWN & Chinese Taipei \\
\hline IRL & Ireland & USA & United States \\
\hline ISL & Iceland & VNM & Viet Nam \\
\hline ISR & Israel & $\mathrm{ZAF}$ & South Africa \\
\hline
\end{tabular}

Source: OECD Input-Output Tables (IOTs) Database, 2018 edition 
Table 7 OECD Input-Output Tables (IOTs) sector classification dictionary (35 sectors: 32 industries and 3 final sectors considered for the computations in the paper)

\begin{tabular}{|c|c|c|c|c|}
\hline$\#$ & Label & ISO & Sector & OECD code(s) \\
\hline 1 & 01T03AGR & AGR & Agriculture, forestry and fishing & D01T03 \\
\hline 2 & 05T09MIN & MIN & Mining, quarrying and supporting services & D05T06; D07T08; D09 \\
\hline 3 & 10T12FOD & FOD & Food products, beverages and tobacco & D10T12 \\
\hline 4 & 13T15TEX & TEX & Textiles, wearing apparel, leather & D13T15 \\
\hline 5 & 16WOD & WOD & Wood and products of wood and cork & D16 \\
\hline 6 & 17T18PAP & PAP & Paper products and printing & D17T18 \\
\hline 7 & 19T21PECH & PECH & Refined petroleum, Chemicals, Pharmaceutical & D19; D20T21 \\
\hline 8 & $22 \mathrm{RBP}$ & $\mathrm{RBP}$ & Rubber and plastic products & D22 \\
\hline 9 & $23 \mathrm{NMM}$ & NMM & Other non-metallic mineral products & D23 \\
\hline 10 & $24 \mathrm{MET}$ & MET & Basic metals & D24 \\
\hline 11 & $25 \mathrm{FBM}$ & FBM & Fabricated metal products & D25 \\
\hline 12 & 26CEQ & CEQ & Computer, electronic and optical products & D26 \\
\hline 13 & $27 \mathrm{ELQ}$ & ELQ & Electrical equipment & D27 \\
\hline 14 & $28 \mathrm{MEQ}$ & MEQ & Machinery and equipment, nec & D28 \\
\hline 15 & 29MTR & MTR & Motor vehicles, trailers and semi-trailers & D29 \\
\hline 16 & 30TRQ & TRQ & Other transport equipment & D30 \\
\hline 17 & 31Т33ОТМ & OTM & Other manufacturing; servicing of machinery / equip. & D31T33 \\
\hline 18 & 35T39EGW & EGW & Electricity, gas, water, sewerage, waste services & D35T39 \\
\hline 19 & $41 \mathrm{~T} 43 \mathrm{CON}$ & $\mathrm{CON}$ & Construction & D41T43 \\
\hline 20 & 45T47WRT & WRT & Wholesale and retail trade; repair of motor vehicles & D45T47 \\
\hline 21 & 49T53TRN & TRN & Transportation and storage & D49T53 \\
\hline 22 & $55 \mathrm{~T} 56 \mathrm{HTR}$ & HTR & Accomodation and food services & D55T56 \\
\hline 23 & $58 \mathrm{~T} 60 \mathrm{PAB}$ & $\mathrm{PAB}$ & Publishing, audiovisual and broadcasting activities & D58T60 \\
\hline 24 & $61 \mathrm{TLC}$ & TLC & Telecommunications & D61 \\
\hline 25 & 62T63ITS & ITS & IT and other information services & D62T63 \\
\hline 26 & $64 \mathrm{~T} 66 \mathrm{FIN}$ & FIN & Financial and insurance activities & D64T66 \\
\hline 27 & 68REA & REA & Real estate activities & D68 \\
\hline 28 & $69 \mathrm{~T} 82 \mathrm{OBZ}$ & OBZ & Other business sector services & D69T82 \\
\hline 29 & $84 \mathrm{GOV}$ & GOV & Public admin. and defence; compulsory social security & D84 \\
\hline 30 & $85 \mathrm{EDU}$ & EDU & Education & D85 \\
\hline 31 & $86 \mathrm{~T} 88 \mathrm{HTH}$ & HTH & Human health and social work & $\mathrm{D} 86 \mathrm{~T} 88$ \\
\hline 32 & 90T980TS & OTS & Arts, entertainment and other service activities & D90T96; D97T98 \\
\hline 33 & $991 X M$ & $\mathrm{XM}$ & Foreign sector (Imports and Exports) & \\
\hline 34 & $992 \mathrm{YC}$ & $\mathrm{YC}$ & Households and Government sector & \\
\hline 35 & 993PI & PI & Profits and Investment sector & \\
\hline
\end{tabular}

Source: Authors' elaboration based on OECD Input-Output Tables (IOTs) Database, 2018 edition

Acknowledgements We gratefully acknowledge the comments and suggestions made by the anonymous referees and guest editors. Responsibility for any errors in the resulting work remains our own.

Open Access This article is licensed under a Creative Commons Attribution 4.0 International License, which permits use, sharing, adaptation, distribution and reproduction in any medium or format, as long as you give appropriate credit to the original author(s) and the source, provide a link to the Creative Commons licence, and indicate if changes were made. The images or other third party material in this article are included in the article's Creative Commons licence, unless indicated otherwise in a credit line to the material. If material is not included in the article's Creative Commons licence and your intended use is not permitted by statutory regulation or exceeds the permitted use, you will need to obtain permission directly from the copyright holder. To view a copy of this licence, visit http://creativecommons.org/licenses/by/4.0/. 


\section{References}

Adger WN (2006) Vulnerability. Glob Environ Chang 16(3):268-281

Blöchl F, Theis FJ, Vega-Redondo F, Fisher EO (2011) Vertex centralities in input-output networks reveal the structure of modern economies. Phys Rev E 83(4):046127

Boley D, Ranjan G, Zhang ZL (2011) Commute times for a directed graph using an asymmetric Laplacian. Linear Algebra Appl 435(2):224-242

Brody A (1970) Prices proportions and planning. Akademiai Kiado, Budapest

Cardinale I (2019) Vulnerability, resilience and 'systemic interest': A connectivity approach. Netw Spat Econ. https://doi.org/10.1007/s11067-019-09462-9

Caschili S, Medda FR, Wilson A (2015) An interdependent multi-layer model: resilience of international networks. Netw Spat Econ 15(2):313-335

Dietzenbacher E, van Burken B, Kondo Y (2019) Hypothetical extractions from a global perspective. Econ Syst Res 31(4):505-519

Duchin F, Levine SH (2010) Embodied resource flows and product flows: Combining the absorbing Markov chain with the input-output model. J Ind Ecol 14(4):586-597

Franceschet M (2011) Pagerank: Standing on the shoulders of giants. Commun ACM 54(6):92-101

Freeman L (1979) Centrality in social networks - conceptual clarification. Soc Netw 1:215-239

Friedkin NE (1991) Theoretical foundations for centrality measures. Am J Sociol 96:1478-1504

Galbusera L, Giannopoulos G (2018) On input-output economic models in disaster impact assessment. Int J Disaster Risk Reduction 30:186-198

Grinstead CM, Snell JL (1997) Introduction to probability. Am Math Soc

Hummels D, Ishii J, Yi KM (2001) The nature and growth of vertical specialization in world trade. J Int Econ 54:75-96

Iyer S, Killingback T, Sundaram B, Wang Z (2013) Attack robustness and centrality of complex networks. PloS ONE 8(4)

Kelly S, Tyler P, Crawford-Brown D (2016) Exploring vulnerability and interdependency of UK infrastructure using key-linkages analysis. Netw Spat Econ 16(3):865-892

Kemeny JG, Snell JL (1976) Finite Markov chains. Springer, New York

Kostoska O, Stojkoski V, Kocarev L (2020) On the structure of the world economy: An absorbing Markov chain approach. Entropy 22(4):482

Leontief WW (1937) Interrelation of prices, output, savings, and investment. Rev Econ Stat 19(3):109-132

Leontief WW (1949) Recent developments in the study of interindustrial relationships. Am Econ Rev 39(3):211-225

Leontief WW (1986) Input-output economics, 2nd edn. Oxford University Press, Oxford

Leontief WW (1991[1928]) The economy as a circular flow. Struct Chang Econ Dyn 2(1):181-212

Leontief WW, Brody A (1993) Money-flow computations. Econ Syst Res 5(3):225-233

McNerney J, Fath BD, Silverberg G (2013) Network structure of inter-industry flows. Physica A Stat Mech Appl 392(24):6427-6441

Meyer CD (2000) Matrix analysis and applied linear algebra. SIAM

Miller RE, Blair PD (2009) Input-output analysis: foundations and extensions, 2nd edn. Cambridge University Press, Cambridge

Moosavi V, Isacchini G (2017) A Markovian model of evolving world input-output network. PloS ONE 12(10)

Morgenstern O (ed) (1954) Economic activity analysis. John Wiley \& Sons, New York

Newman ME (2005) A measure of betweenneess centrality based on random walks. Soc Netw 27(1):39-54

Newman ME (2010) Networks: An introduction. Oxford University Press, New York

Noh JD, Rieger H (2004) Random walks on complex networks. Phys Rev Lett 92(11):118701-1-4

Olsen JA (1992) Input-output models, directed graphs and flows in networks. Econ Model 9(4):365-384

Palacios JL (1990) Bounds on expected hitting times for a random walk on a connected graph. Linear Algebra Appl 141:241-252

Piccardi C, Riccaboni M, Tajoli L, Zhu Z (2018) Random walks on the world input-output network. J Complex Netw 6(2):187-205

Ranjan G, Zhang ZL (2013) Geometry of complex networks and topological centrality. Phisica A 392:3833-3845 
Solow R (1952) On the structure of linear models. Econometrica 20(1):29-46

Timmer M (2012) The World Input-Output Database (WIOD): Contents, Sources and Methods, wIOD Working Paper Nro. 10, available at: http://www.wiod.org

Tsekeris T (2017) Network analysis of inter-sectoral relationships and key sectors in the Greek economy. J Econ Interac Coord 12(2):413-435

UN (2009) System of National Accounts 2008 ST/ESA/STAT/SER.F/2/Rev.5. United Nations, New York Venables WN, Ripley BD (1999) Modern applied statistics with S-PLUS, 3rd edn. Springer-Verlag, New York

Wilson RJ (1972) Introduction to graph theory. Oliver \& Boyd, Edinburgh

Xing L, Dong X, Guan J (2017) Global industrial impact coefficient based on random walk process and inter-country input-output table. Physica A Stat Mech Appl 471:576-591

Xing L, Guan J, Wu S (2018) Measuring the impact of final demand on global production system based on Markov process. Physica A Stat Mech Appl 502:148-163

Xu M, Allenby BR, Crittenden JC (2011) Interconnectedness and resilience of the US economy. Adv Complex Syst 14(05):649-672

Publisher's Note Springer Nature remains neutral with regard to jurisdictional claims in published maps and institutional affiliations.

\section{Affiliations}

\section{Ariel L. Wirkierman ${ }^{1}$ (D) - Monica Bianchi ${ }^{2} \cdot$ Anna Torriero $^{2}$}

Monica Bianchi

monica.bianchi@unicatt.it

Anna Torriero

anna.torriero@unicatt.it

1 Institute of Management Studies (IMS), Goldsmiths, University of London, London, UK

2 Dipartimento di Matematica per le Scienze Economiche, Finanziarie ed Attuariali, Università Cattolica del Sacro Cuore, Milano, Italy 